\title{
LA-UR-17-20317
}

Approved for public release; distribution is unlimited.

Title: $\quad$ Experimental Physical Sciences Vitae 2017

Author(s): $\quad$ Kippen, Karen Elizabeth

Del Mauro, Diana

Patterson, Eileen Frances

Fronzak, Hannah Kristina

Cruz, James Michael

Kramer, Robert W.

Martin, Genevieve

Robinson, Richard Cecil

Trujillo, Carlos Genaro

Valdez, Sandra M.

Intended for: Publication

Web

Issued: 
Disclaimer:

Los Alamos National Laboratory, an affirmative action/equal opportunity employer, is operated by the Los Alamos National Security, LLC for the National Nuclear Security Administration of the U.S. Department of Energy under contract DE-AC52-06NA25396. By approving this article, the publisher recognizes that the U.S. Government retains nonexclusive, royalty-free license to publish or reproduce the published form of this contribution, or to allow others to do so, for U.S. Government purposes. Los Alamos National Laboratory requests that the publisher identify this article as work performed under the auspices of the U.S. Department of Energy. Los Alamos National Laboratory strongly supports academic freedom and a researcher's right to publish; as an institution, however, the Laboratory does not endorse the viewpoint of a publication or guarantee its technical correctness. 


\section{Experimental Physical Sciences}

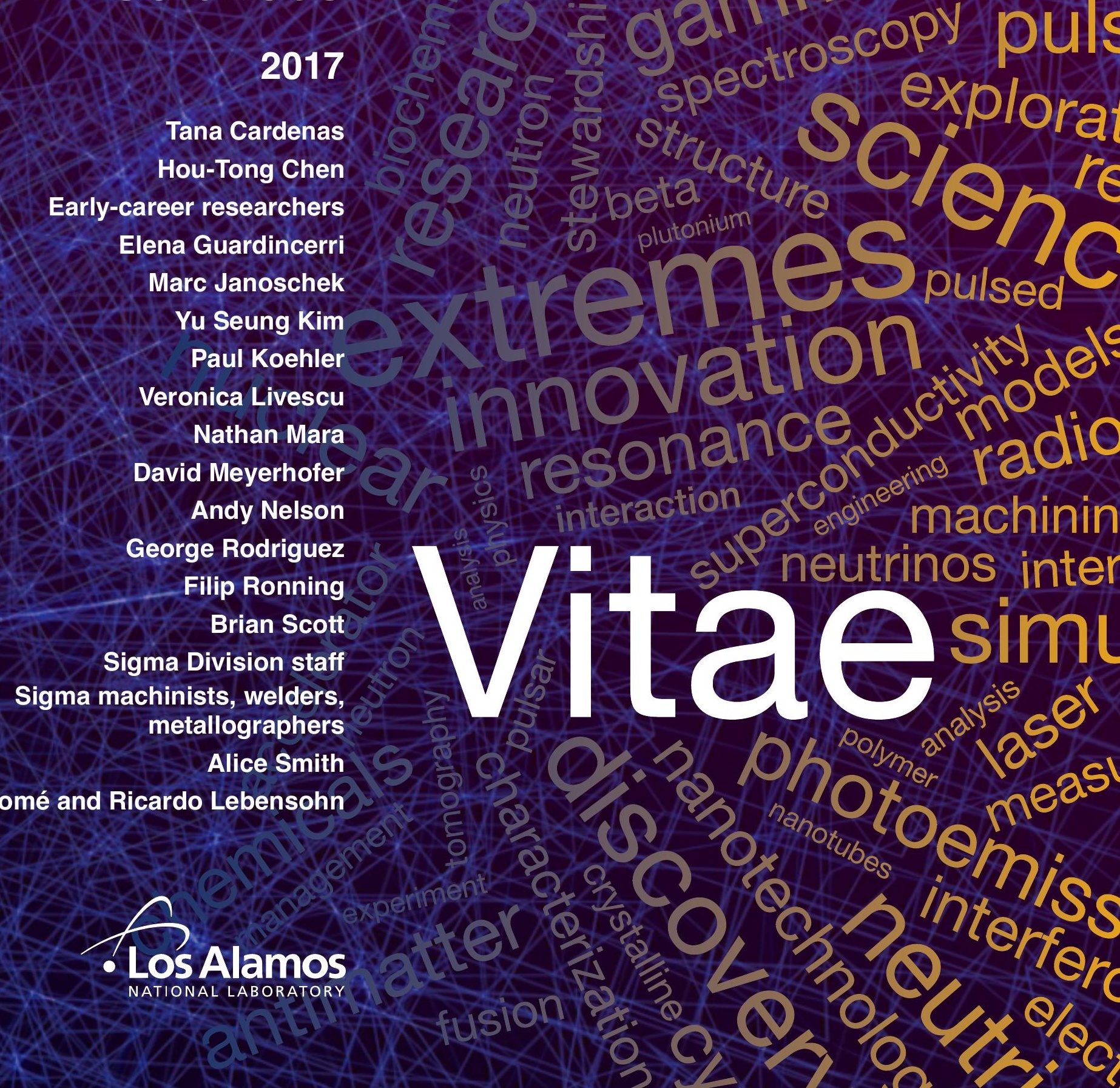




\section{Experimental Physical Sciences Directorate at Los Alamos National Laboratory}

Advancing physics and materials science

for problems of national importance

Frequently our most basic research experiments stimulate solutions for some of the most intractable national security problems, such as nuclear weapons stewardship, homeland security, intelligence and information analysis, and nuclear and alternative energy.

This publication highlights our talented and creative staff who deliver solutions to these complex scientific and technological challenges

by conducting cutting-edge multidisciplinary physical science research. 


\section{Tana Cardenas Engineering solutions to national security challenges}

As a child in Galisteo, New Mexico, Tana Cardenas liked to walk around the house with a screwdriver, tightening every loose screw she saw. And, when she was eight years old, she said she remembered, "Someone asked me what I wanted to be, and I said, 'I'm going to be a mechanical engineer."'

Cardenas was true to her word. She is now an R\&D engineer on the Target Engineering team in Engineered Materials (MST-7) where she designs targets Los Alamos physicists put in the path of lasers at the National Ignition Facility (NIF) at Lawrence Livermore National Laboratory and the Omega laser facility at the University of Rochester. The experimental campaigns at NIF and Omega serve Stockpile Stewardship and the efforts to achieve ignition: energyproducing inertial confinement fusion.

Derek Schmidt, an MST-7 senior target engineer Cardenas considered her mentor, said he sees her as a bright, hard-working engineer possessed of natural leadership ability. "She is leading some of our most visible and critical campaigns for LANL," he said, "and doing a spectacular job balancing customer service and professionalism within our stressful working environment."

Cardenas's projects include the Marble and Double Shell projects, which focus on how the material mix in a target's physics package reacts to shock and intense radiation. Her work begins when physicists bring her their target specifications.

She translates their ideas into reality and produces an initial design that is then altered and refined in collaboration with the clients. "We meet frequently to make sure I'm accurately interpreting what they need," she said, "but it's always a balance between what they want and what is physically possible. I help them meet the balance."

Cardenas uses computer-aided design software to draw, at the size of a monitor screen, targets that will be small enough to perch on a fingertip. The same software lets her digitally assemble the target and place it in a virtual mockup of the NIF or Omega target chambers. Both NIF and Omega may host a project's completed targets because NIF experiments are often preceded by shots on Omega.

"You get only two or three shots at a time on NIF," Cardenas explained, "and it's very expensive. By trying some things out on Omega, the researchers get more data at less cost and learn new pieces to validate their codes. Then at NIF, their shots are more robust because they've practiced on Omega.

For finished target designs, external companies fabricate some of the components, such as the capsules and simple

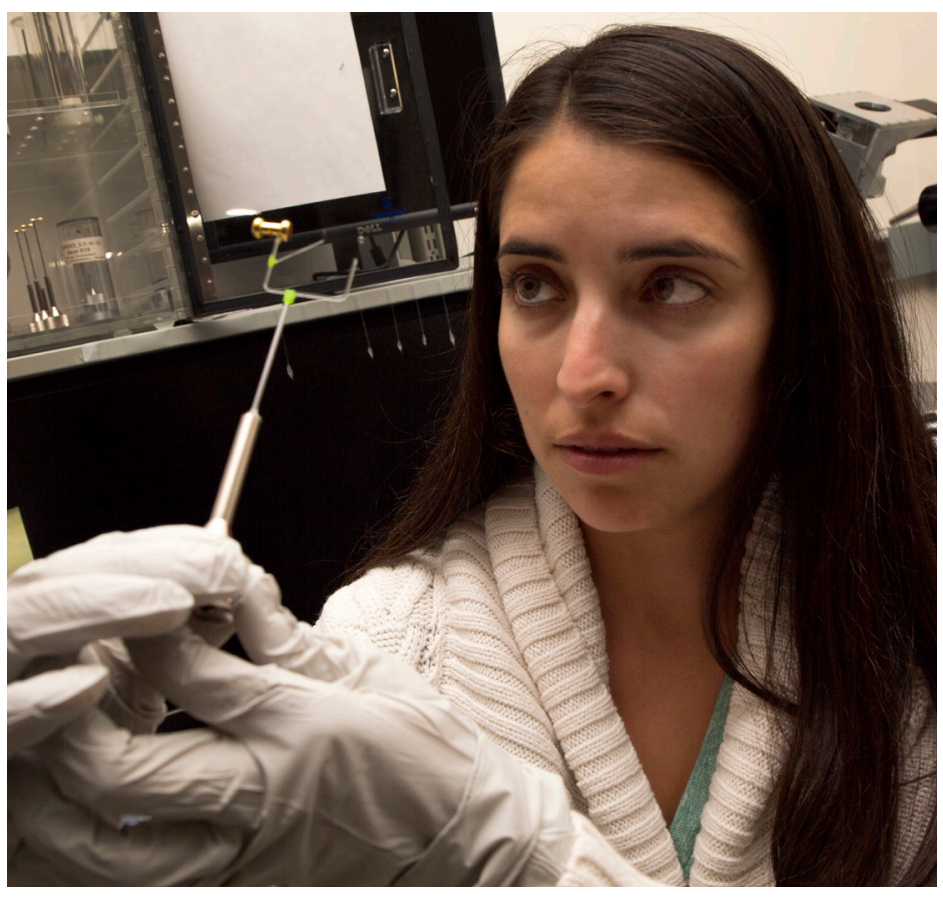

Tana Cardenas at work on a target for an opacity shot at the National Ignition Facility.

components. Fellow team members at the Target Fabrication Facility machine many of the other, more developmental components. Cardenas helps orchestrate the manufacturing time for all the processes and works closely with machinists and scientists to solve any problems. The facility also houses target assembly, an exacting procedure requiring magnified optics and custom robotic stages as well as the use of toothpicks and thin glue sticks for positioning and adhering all the parts.

Projects also need what Cardenas called "rudimentary objects." These trussed structures are designed for holding and positioning target components in the assembly. She designs and models these for additive manufacturing. Her work space has additive machines, but if an object will be used at NIF, an outside company produces it, using a proprietary NIF-approved substance called MicroFine Green. Cardenas has noticed that those objects tend to come back slightly oversized, so she accounts for the sizing anomaly in her designs.

A challenge facing Cardenas and her fellow team members is related to the Double Shell project, which is named for the double-shelled target it requires. Designing that target to be successfully machined is difficult because the target will include a tube that could easily be broken. The design and assembly methods have to accommodate that tube. "I have no idea how we'll do that," Cardenas said, and then smiled. "But we will." 


\section{Houl-Tong Chen Bringing the possibilities of metamaterials to light}

For a decade, futuristic invisibility cloaks, bendable light, and superlenses defying diffraction limits have tantalized materials physicists who build tiny artificial structures called metamaterials, hoping to master their unnatural properties.

"Maybe after another 10 years, they'll find cloaking very useful for making things disappear, like airplanes, and freak everyone out!" said Hou-Tong Chen, a member of the nanophotonics and optical nanomaterials thrust at the Center for Integrated Nanotechnologies (CINT).

He's sticking with more tangible aspects of metamaterialsa set of properties that can manipulate electromagnetic polarization states and direct how light travels (think lenses, prisms) without the use of curved materials. His research keeps him running between his office, where he builds models on his computer; the CINT clean room, where he fabricates metamaterials samples; and his laser lab, where he tests his creations.

The lure is flat optics, which employ flat lenses made of metamaterials instead of conventional curved lenses. By themselves, quantum dots and graphene don't interact strongly enough with light, severely limiting the functionality of optical devices. But, "if we can integrate those materials with metamaterials, we can engineer the response," Chen said. "Their performance can be enhanced dramatically and give us more opportunities to create multifunctional devices."

Instead of the intricate prisms and bulky geometric shapes found in conventional lenses, he said, pointing to his eyeglasses, metamaterials as flat as a single sheet of paper would focus light, alter polarization, and steer the light in different directions over a broad frequency range. Most importantly, since thin-layered metamaterials absorb little light, they would overcome the pitfall of bulk metamaterials, which absorb too much energy to be practical.

"We want to develop the individual components that are necessary to build a flat optics system for applications such as short-range communications and imaging," Chen said. "It can be done, that has been proven," he said-but will the imaging be sharp and fast enough for scientific instruments and satellites?

The U.S. Department of Defense lists metamaterials as a high priority research area, and the National Reconnaissance Office has funded Chen and his collaborators for a yearlong proof-of-principle study to determine how metamaterial-based thin films could be used in satellite antennae. The aim is lightweight, foldable satellites that would replace hefty satellite dishes.

"My entire career has been focused on metamaterials," said Chen as he opened boxes containing custom-designed

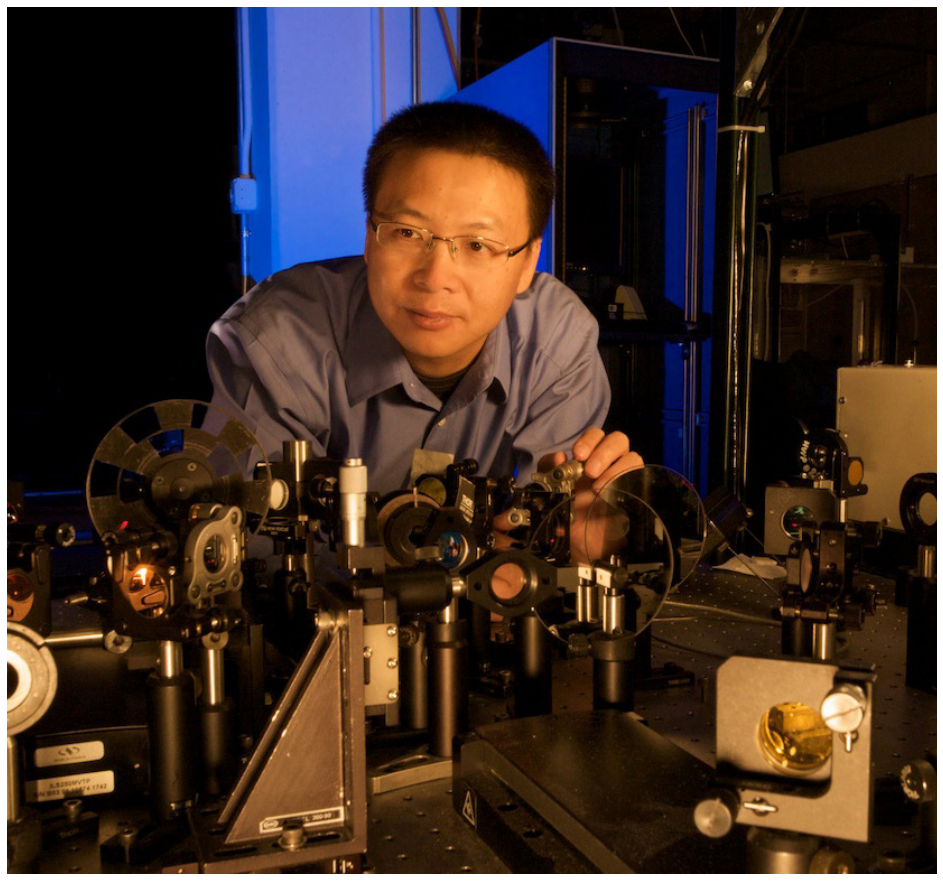

In his laser lab, Hou-Tong Chen tests metamaterials, which can be used to manipulate electromagnetic waves. Detectors capture the spectral response of the metamaterials and record the signals on a nearby computer screen.

gold and silver layered metamaterials he made the size of computer chips. When he entered the field after earning his PhD in physics from Rensselaer Polytechnic Institute in 2004, metamaterials were thought to be passive, with no on or off switch. As a CINT postdoctoral researcher at Los Alamos, he pioneered a control knob by which he could adjust how metamaterials respond to changes in voltage, light excitation, and temperature - thereby scoring his first Nature paper.

"I know him first through his pioneering paper in optical switching of THz metamaterials by using optical excited carriers in a semiconductor," said Lawrence Berkeley National Laboratory Materials Sciences Division Director Xiang Zhang. "This is a very clever idea, and basically opened the field of optically switchable metamaterials that is now a mainstream topic."

A terahertz beam can't focus tight like a microscope, a serious shortcoming, so Chen is pursuing the optical frequency range. In a \$1.8 million-a-year Laboratory Directed Research and Development project, he leads a three-year quest for new meso-photonic materials that could control the functionality of light-matter interactions, benefitting solar cell energy harvesting as well as global security communications, imaging, and sensing. "I'm happy the Lab is supporting it because metamaterials are not commercialized yet, so funding sources are quite scarce," Chen said. 


\section{Early-career researchers}

Meet Physics Division's newest staff researchers: Jennifer Schei (Applied Modern Physics, P-21); John Goett and Patrick Younk (Neutron Science and Technology, P-23); and Matthew Durham and Elena Guardincerri (Subatomic Physics, P-25).

After experiencing Los Alamos National Laboratory as postdoctoral researchers, they chose to continue their careers here for a host of compelling reasons, including the opportunity to

- pursue a mixture of basic and applied science,

- expand on their fulfilling postdoctoral research experiences,

- design and perform experiments using the Laboratory's exceptional scientific tools and facilities,

- collaborate in the impressive research being performed by their colleagues,

- participate in multi-institution scientific and technical projects led by the Laboratory, and

- live and work in an outdoors-centric, family-friendly community.

Becoming a Los Alamos staff scientist is no small accomplishment in the competitive world of national laboratory research. Postdoctoral researchers must demonstrate exceptional scientific abilities based on work performed, research published and presented, and interactions with colleagues. Division management selects the most promising candidates while considering diversity and the programmatic and strategic needs of its groups, the Division, and the Laboratory. Read on to get acquainted with the newest Physics Division staff members.

\section{Jennifer Schei}

\section{Applied Modern Physics, P-21}

\section{Foray into physics}

I grew up in Anoka, Minnesota, and really enjoyed courses in math and science, but I didn't have much exposure to careers in those fields. When I went off to college, I initially thought of majoring in elementary education, because I didn't know what types of careers I could pursue with a science degree other than teaching. My dad, who knew me better than I knew myself at that point, encouraged

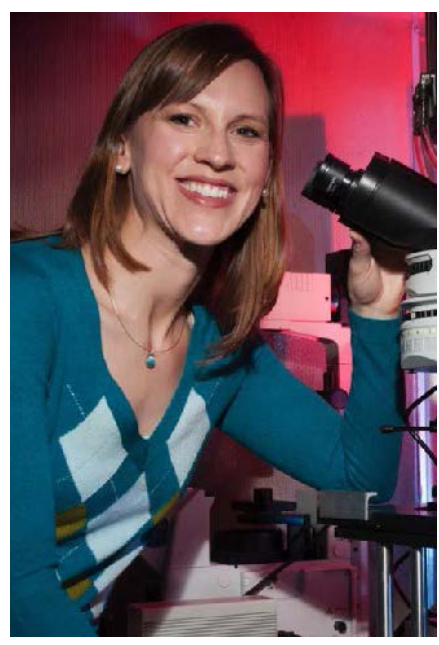
me to major in physics. I took the risk and changed my major from elementary education to physics the first week of my first year, having never taken a course in physics. I haven't looked back. I earned a BA in physics from the

\section{their careers toward the Laboratory}

College of St. Benedict and St. John's University in Minnesota. Afterwards, I earned an MS and PhD in physics from Washington State University. My graduate work under Dr. David Rector, a former Los Alamos staff member, and Dr. Matthew McCluskey involved developing optical methods to image the brain, which we used to study the function of sleep.

\section{Nature and neural activity}

I came to Los Alamos National Laboratory as a postdoc to work on a Laboratory Directed Research and Development (LDRD) project developing three-dimensional nanowire electrode arrays to measure neural activity. I found the project cutting edge, and I was impressed with the collaboration opportunities with people in different areas of expertise. During my interview visit I was also impressed with the collaborative opportunities that Los Alamos offers. Of course, the beauty of the area was a benefit as I enjoy the outdoors.

My most memorable time as a postdoc was participating in the Science of Signatures Advanced Studies Scholars program hosted by the Engineering Institute at Los Alamos. A small group of us with different backgrounds were given a project completely out of our fields of expertise and three weeks to come up with a solution. This experience was really fun and exciting - to submerge ourselves into a new field and come up with some out-of-the-box ideas. For me, this program highlighted the strengths of Los Alamos where cross-disciplinary collaboration is common and encouraged. I found that I enjoyed and thrived in this type of environment and wanted to stay at the Lab.

\section{Radiographic physics}

My science career started with space physics, migrated to biophysics, and is currently in coding and radiographic physics. Each of these experiences was a serendipitous happening that led to the next great opportunity.

As a new hire, I am developing software for the Bayesian inference engine, which is used to analyze radiographic images of implosions of mockup nuclear weapons taken at the Dual-Axis Radiographic Hydrodynamic Test Facility. I also do some work on radiographic image analysis, which increases our image reconstruction capabilities.

\section{Best career advice}

Never underestimate the power of networking. As an introvert, it can be exhausting to meet new people, especially in large groups. I have to put on my confidence and force myself to initiate a conversation with someone new. Many of my great opportunities have been a result of networking. You never know where the road will lead next and what you can learn from someone else. 


\section{John Goett}

\section{Neutron Science and Technology, P-23}

\section{P-squared}

I studied philosophy and physics at Rensselaer Polytechnic Institute in Upstate New York. My dissertation work was on precision antineutrino flux measurements at nuclear reactors.

\section{Neutrino mysteries}

I sought out a postdoctoral position at Los Alamos because I wanted to work with the Weak Interactions Team on the neutrinoless double beta decay search we call the

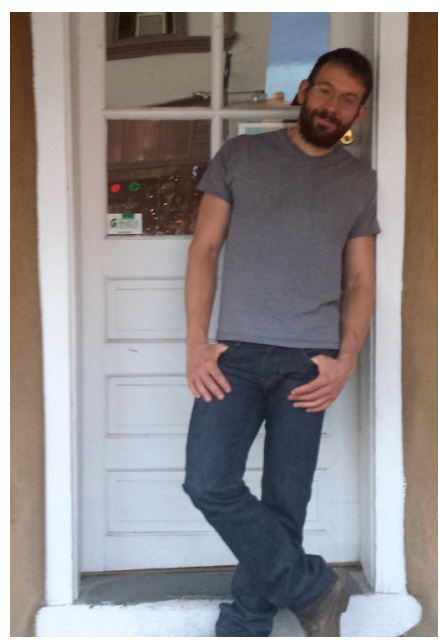

Majorana Demonstrator project. Neutrinoless double beta decay is a theoretical process that has not been observed, but is intriguing to particle physicists because it offers simple explanations to questions about neutrino mass and the observed matter/anti-matter asymmetry in the universe. The demonstrator is an R\&D program to field technologies we could use in the ultimate search.

\section{SURF rider}

My most memorable day as a postdoc was the first day I went underground at our laboratory in Lead, South Dakota. I've spent the better part of the last decade working deep underground, but SURF [for Sanford Underground Research Facility] is special. It's a relatively new facility, and everything there, from the science being done to the folks who keep the place going, is pretty unique.

\section{Collaborative science}

As a staff member, I like working with folks who come from different disciplines. You can discover quite a lot by attacking a technical problem with someone who doesn't think like you. For example, right now l'm working on a bolometer design that uses phonon time-of-flight and caustics to do particle identification. If I hadn't started talking to materials scientists who think about heat transfer in a more detailed way than I used to, I never would have explored this idea.

\section{Universal impact}

My passion is for precision instrumentation and sensor development. I'm soaking up as much expertise as I can on imaging technologies for developing next generation cameras relevant to the Lab's missions. I'm also trying to develop a new detector technology that, if successful, could do good things for basic research in neutrino and dark matter science as well as nuclear nonproliferation.

\section{Best advice}

Frans Trouw (Subatomic Physics, P-25) had done a lot to help me get an ambitious research project off the ground. Probably the most important thing he is teaching me is the difference between efficiency and effectiveness. People can get taken away with the simplicity and beauty of a completed structure, and put a lot of energy into gutting the structure of all its scaffolding and making it look just so. It doesn't matter if it's a piece of apparatus or an idea. At the end of the day, it's the function of the thing that matters. Did you get the measurement, or did you fuss with some cool widget?

\section{Patrick Younk}

\section{Neutron Science and Technology, P-23}

\section{The U.P.}

I was born and raised in Norway, Michigan, a small town in the Upper Peninsula (a.k.a., the Great White North, eh?!). I spent eight years working as an engineer in industry before going back to school to get a PhD in physics from Michigan Technological University.

\section{Soaring with HAWC}

I was interested in conducting research associated with the High-Altitude Water

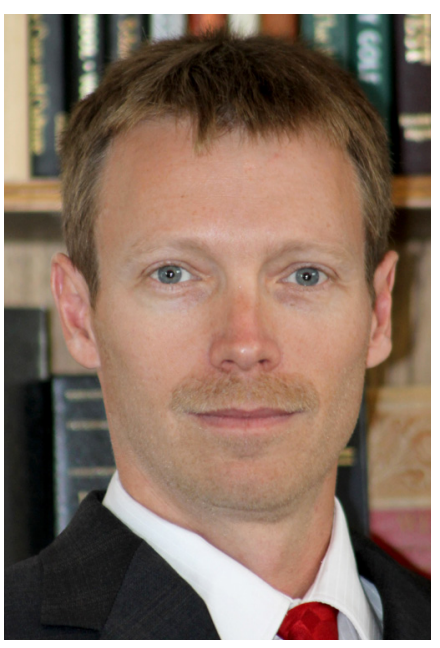

Cherenkov (HAWC) gamma-ray observatory, a new instrument that was to be built on a mountain in Mexico. Los Alamos was a leading institute in the HAWC collaboration, and I had a lot of respect for my prospective boss, Brenda Dingus. I was offered a Director's Postdoctoral Fellowship; it was a great opportunity for me.

One memorable day was April 15, 2012. We started construction on the detector array for HAWC, and my job was to provide the initial instruction to a team of eight Mexican farmers on how to build a world-class astrophysics observatory in the thin air at 13,500 feet above sea level-and I don't speak Spanish. Suffice it to say, I had a great team of workers, and the observatory was built to specification and on time.

Brenda Dingus was my first mentor at the Lab. Another person I would like to mention is David Holtkamp, a consummate experimentalist who got me interested in work associated with stockpile stewardship, and I cannot thank him enough for the opportunities he has thrown my way. 


\section{Stockpile stewardship}

As a researcher, I have always liked being involved in different projects from basic to applied research. The Lab is a great place if you have broad interests in science and technology. Also, the Lab lets you quickly take on leadership roles in programmatic projects.

As a staff scientist, my current project is fielding optical velocimetry diagnostics on a series of subcritical experiments at the Nevada National Security Site, to support the Lab's stockpile stewardship charge. I often work in a mine, which is interesting because before I was working on a mountain. I am particularly excited about applying ultrafast optical ranging technology to several diagnostic challenges associated with stockpile stewardship, with applicability to the general scientific instrumentation community.

\section{Matthew Durham}

\section{Subatomic Physics, P-25}

\section{From hill country to Long Island}

I was born in Austin and went to the University of Texas, where I received a BS in physics in 2005. After that, I went to Stony Brook University in New York and worked at Brookhaven Lab for my PhD in physics.

\section{Detecting an opportunity While working on my thesis experiment I got to know sev- eral staff members and post-} docs that were part of P-25. I

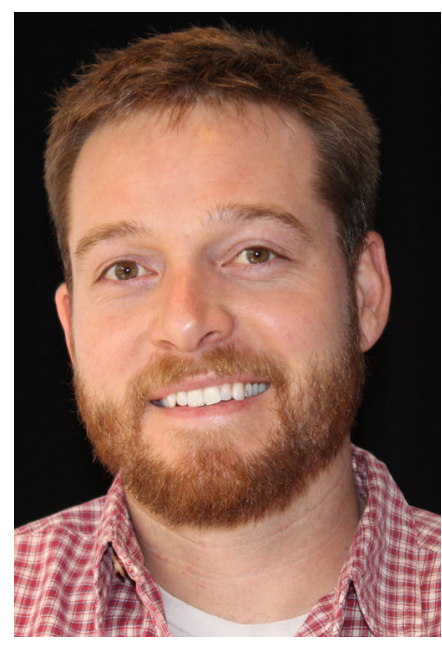
was very impressed with their work and the leadership role that the Los Alamos group played in our experiment. This led me to look for a postdoc in the group, and it worked out. My main task as a postdoc here was work on a new silicon detector for PHENIX (Pioneering High Energy Nuclear Interaction eXperiment) at the Relativistic Heavy Ion Collider. It is an extremely complex device with more than a million readout channels that P-25 has worked on for a decade. The first time we installed the entire detector and took data was a big deal for me.

\section{Early-career support}

When I was first hired as a postdoc, my team leader was Melynda Brooks, who was in charge of the detector upgrade at PHENIX. I was constantly impressed with both her technical leadership and ability to manage a group of people from various institutions to make such a large, complicated project a success. The entire P-25 PHENIX team was very supportive of me and gave me the freedom to work on what I found interesting, along with all the tools that I needed to succeed.

\section{Staying power}

At Los Alamos, I am able to work on basic physics research as well as help solve problems in the national interest. The mix of basic and applied science that we are able to do here is hard to find in other places. Plus, Los Alamos is a great place to live and raise my two daughters. Harnessing cosmic rays to solve tough challenges I spend most of my time now on muon tomography, where we use natural radiation from cosmic rays to image the interior of dense objects. We are applying this technique to several problems in arms control and treaty verification, and we're using it to aid the cleanup of the Fukushima Daiichi nuclear power plant in Japan.

\section{Elena Guardincerri}

Subatomic Physics, P-25

\section{To read more about Elena Guardincerri and her work tracking muons to reduce nuclear threats and help preserve architectural trea- sures, see the next page.}

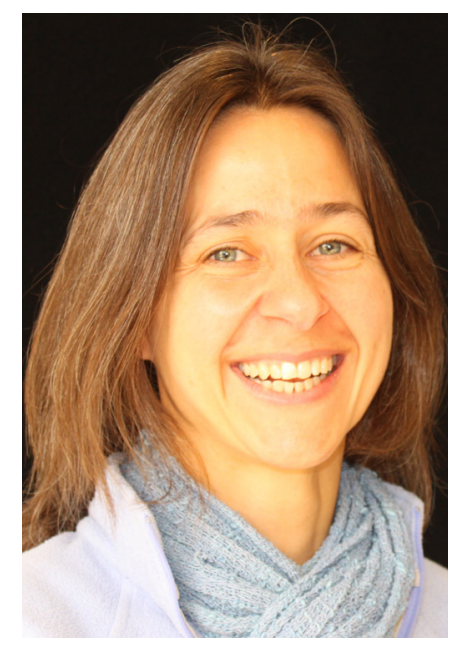




\section{Elena Guardincerri}

When Elena Guardincerri was a physics PhD student at the University of Genova, she considered muons a nuisance. She built muon detectors to snare these secondary cosmic rays, which were interfering with her experiments to study elusive neutrinos. Now, as a member of the Subatomic Physics (P-25) Muon Tomography team, she is developing a muon detector to assist in saving a 37,000-ton masonry cathedral dome, known as il Duomo, in Florence, Italy, from severe cracks and earthquake damage. Her novel method uses muons as a probe to image reinforcement elements inside thick walled structures.

"Elena is an extremely creative physicist," said her team leader Chris Morris, who invented multiple scattering muon imaging, which exposes smuggled nuclear material even when it is concealed by shielding material.

Muons can identify dense objects and make distinctions between substances, such as water and melted nuclear fuel, and unlike x-rays, they can penetrate deep inside materials, allowing images of thick objects. Cosmic muon radiography does all of this without damaging structures and without the need of an artificial radiation source.

Guardincerri helped write software for the muon trackers built in Japan by Toshiba that will obtain precise images of the Fukushima Daiichi nuclear power plant, a critical step before disaster cleanup can begin safely. In other high profile work, Guardincerri is "contributing enormously to the Physics Division threat reduction effort," Morris said. For instance, she is testing how well muons can scout for nuclear weapons effects underground.

Guardincerri credits former team member Cas Milner for proposing muon tomography for the dome-one of several ideas the Lab presented to an Italian delegation of conservation experts in 2013.

Designed by the secretive master builder Filippo Brunelleschi, the 15th-century dome of Santa Maria del Fiore Cathedral is an architectural marvel, and it is has been affected by ever-expanding cracks for centuries. Some scholars believe, based on historical documents, that iron reinforcements might be inside the dome's thick masonry, but investigations with metal detectors failed to yield conclusive evidence either for or against this view. To determine the dome's strength and need for further reinforcements, the cathedral's preservationists are looking to Los Alamos to help determine the exact location of the iron-if it exists-and compile a more detailed crack profile, which will be used in their models.

In 2015, Guardincerri visited Florence to explain to the cathedral's conservation committee why she believes the Lab's muon tracker technology could provide precious information regarding the inside of the dome. She presented vivid images of iron bars embedded in a replica wall built at applications around the globe

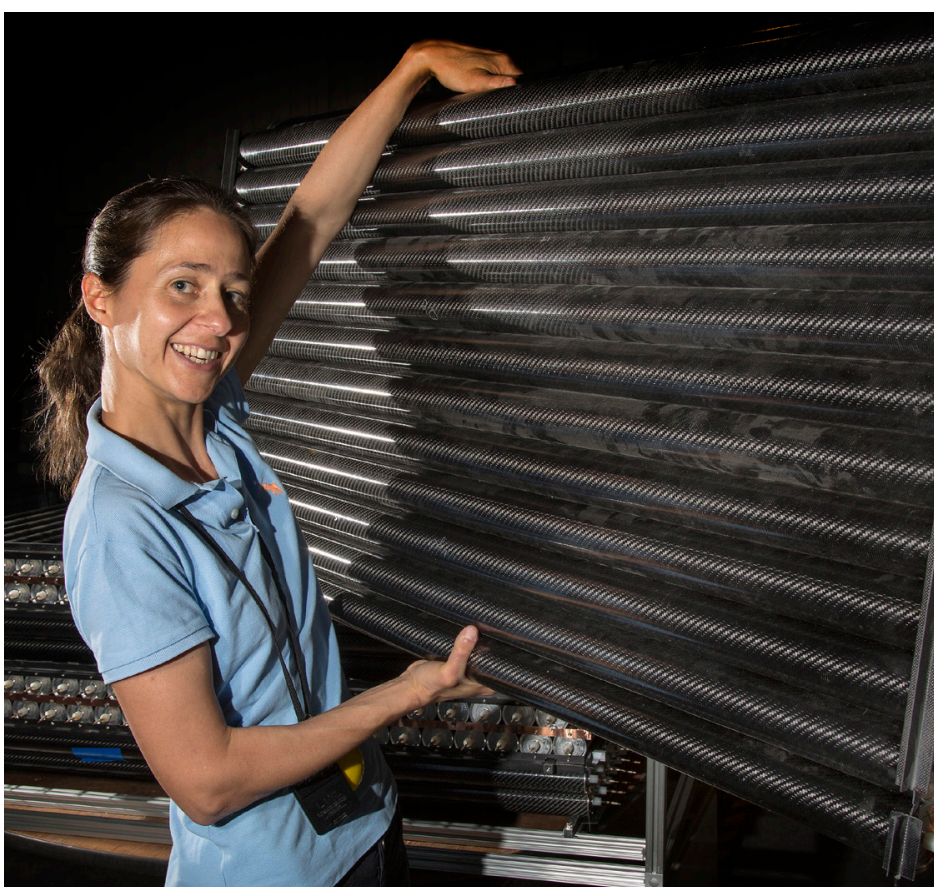

To reveal structural secrets of the Florence cathedral and help protect it against further damage, Elena Guardincerri is designing lightweight muon trackers made of 2-inch-diameter carbon fiber drift tubes for measuring the dome's thick-walled passageways.

Los Alamos. The committee approved the design of a pair of portable trackers, each weighing no more than 220 pounds, one of which will be suspended inside the cathedral near Giorgio Vasari's Last Judgment fresco.

"This will be a great stage to show the world that this [muon imaging] works," said Guardincerri, who grew up in a nearby town.

With Laboratory Directed R\&D Early Career Award funding, she is redesigning the muon trackers, which currently weigh 800 pounds each. Following a recent visit to the National Geographic Society, she and National Geographic are exploring ways to collaborate on the project based on a mutual interest in innovative imaging technology as well as in the history of Florence.

She and colleague Matt Durham (P-25) explained how the one-detector method that has been used for pyramids is better for a wider field of view and the award-winning Los Alamos technology is better for seeing details in smaller structures. By sandwiching a structure between two detectors and measuring the muon rays entering and exiting a structure, the Los Alamos muon tracker distinguishes dense objects with a resolution that other muon imaging methods cannot achieve. For the dome application in particular, "our technique is more accurate and the spatial resolution is much better," Guardincerri said.

Originally published March 2016 


\section{Marc Janoschek Piecing together the}

In the spirit of the Where's Waldo series, imagine the adventures of Los Alamos materials physicist Marc Janoschek, whose globetrotting involves intense experiments for days at a time at neutron sources in the United States, Switzerland, France, and his native Germany. Janoschek most frequently works on uranium or cerium compounds, which exhibit mystifying physics similar to that of plutonium due to their complex electronic configuration. Look for him next in Japan and Australia.

"It's exciting to go to different places and work with different people and a different set of instruments," said Janoschek, a member of Condensed Matter and Magnet Science (MPACMMS), who conducts his research at Los Alamos and elsewhere to get the best possible results.

MPA-CMMS "has an outstanding international reputation in strongly correlated electron physics. I knew all the papers, and I had met some of the scientists at conferences," said Janoschek, who was recruited in 2011 to head the group's neutron scattering capability. "I loved the idea of a group that combines materials synthesis with a large suite of complementary characterization techniques to make progress in the understanding of novel materials. Another plus is I can just go across the street and have discussions with my theory colleagues."

Los Alamos Fellow Joe Thompson (MPA-CMMS) searched for three years for a neutron scattering expert who could use such expertise to expose the complexity of electronically correlated materials under various extreme conditions. He found Janoschek at the University of California, San Diego, where he was a postdoctoral fellow of Germany's Alexander von Humboldt Foundation. Thompson recruited him for a U.S. Department of Energy project on complex electronic materials relevant to research on emergent phenomena. "He was a great find," Thompson said. "He was worth the wait."

As part of Janoschek's doctoral thesis, he designed and built a first-of-its-kind polarimeter to enable magnetic structure and interaction studies in unprecedented detail. Two European neutron scattering centers use his novel device, for which he won the 2014 Wolfram-Prandl Prize. Janoschek said that experience taught him how to endure frustrationa resiliency he drew on recently to achieve what some in his field are calling "the most significant measurement on plutonium in a generation." It resolved the electronic ground state of delta plutonium for the first time, making significant progress on the understanding of plutonium's complex structural, electronic, and magnetic behavior. "The processes that take the most frustration also give you the most reward afterward," he said, summing up lessons he has learned. "Not so many things are impossible-it's just that our approach is from the wrong perspective."

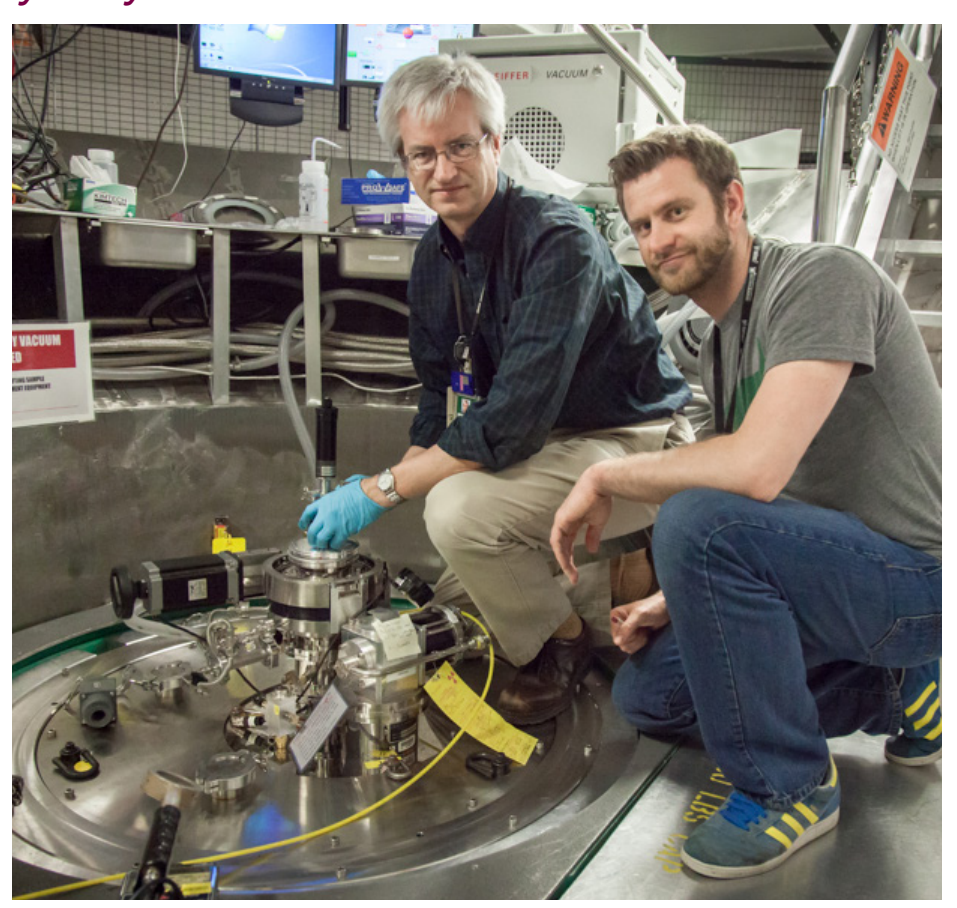

Marc Janoschek (right) secures an average of 50 days a year of neutron beam time at facilities around the globe. Here, he performs a breakthrough plutonium experiment at Oak Ridge National Laboratory with collaborator Doug Abernathy.

It took two years - and the contributions of many - to develop uncrackable safety vessels and to complete the intricate experimental design, which he refined during trial runs at the Lujan Center using the Pharos inelastic neutron scattering instrument. "Neutron scattering experiments on plutonium compounds are exceptionally difficult because plutonium absorbs neutrons easily, which means the data are not very reliable," Janoschek said. "You have to use special tricks to circumvent that."

Today, Janoschek is excited about studying skyrmions, a continuation of his thesis research. He is pioneering ways to design materials with controllable functionality through these vortex-like magnetic objects, created and manipulated inside a material. Up to 100 nanometers in size, skyrmions offer the advantage of ultra-low power consumption. The research is funded by the Laboratory Directed Research and Development program and in line with the Lab's materials strategy and Department of Energy grand challenges in mesoscale science.

"Just as different combinations of atoms produce materials with different properties, different arrangements of skyrmions lead to distinct functionalities through coupling to electrical currents, magnetic and electrical fields, and temperature gradients," he said. "They have exceptional potential for computing, memory storage, and sensing applications." 


\section{Yu Soung Kim Breaking through the status quo in fuel cell technology}

One October morning, chemical engineer Yu Seung Kim and postdoctoral researcher Kwan-Soo Lee arrived for what they thought would be a routine visit with their sponsor. To their astonishment, Assistant Secretary David Danielson of DOE's Energy Efficiency and Renewable Energy (EERE) program pulled up a slide featuring the co-inventors' novel fabrication technique for improving critical fuel cell components. "This is a great example," said Danielson, of how EERE-funded projects have made an impact in industry. For the emerging hydrogen-powered vehicle market, Giner Inc. is preparing to manufacture fuel cell and electrolyzer components based on Kim and Lee's patented methods.

Danielson later called Kim to the front of the conference room for special recognition. Receiving public accolades from his sponsor was a career high point for Kim (Materials Synthesis and Integrated Devices, MPA-11), who has amassed patents, publications, and awards during a decade in the Los Alamos fuel cell program. Kim's work at Los Alamos has been funded by EERE's Fuel Cell Technologies Office. "I didn't expect to be recognized because this (project) just started," he said, noting other inventions Danielson praised that day were mature collaborations with larger companies.

Tied into that moment is Kim's appreciation of new financial incentives the U.S. Department of Energy is offering to fast track the transfer of inventions from national labs to the private sector through licensing agreements. In May, Giner and Kim's research team received EERE's first-ever technologyto-market Small Technology Transfer Research (STTR) award. The funding cemented a nine-month research and development partnership to propel the Los Alamos technology into the marketplace.

"The benefits are for both the national lab and for Giner," said Hui Xu, a program manager at the Boston-based company and former MPA-11 postdoctoral researcher. "There are many brilliant people at national laboratories. They have the great ideas and technologies, and Giner knows how to commercialize these technologies." By collaborating with industry, Los Alamos researchers facilitate their inventions going from prototype to mass market: in this case, fuel cells destined for use in low-emission vehicles for everyday people. As part of its national security mission, Los Alamos leads materials advances in sustainable energy generation, including methods that reduce greenhouse gasses and air pollution.

These days, Giner and Los Alamos are working through the kinks of scaling up Kim's new approach to building the membrane-electrode assembly (MEA). The chemical reaction that generates electricity in a polymer electrolyte membrane (PEM) fuel cell originates in the MEA, which transmits protons between two electrodes. For decades, water-based Nafion dispersion has been the industry standard for electrode

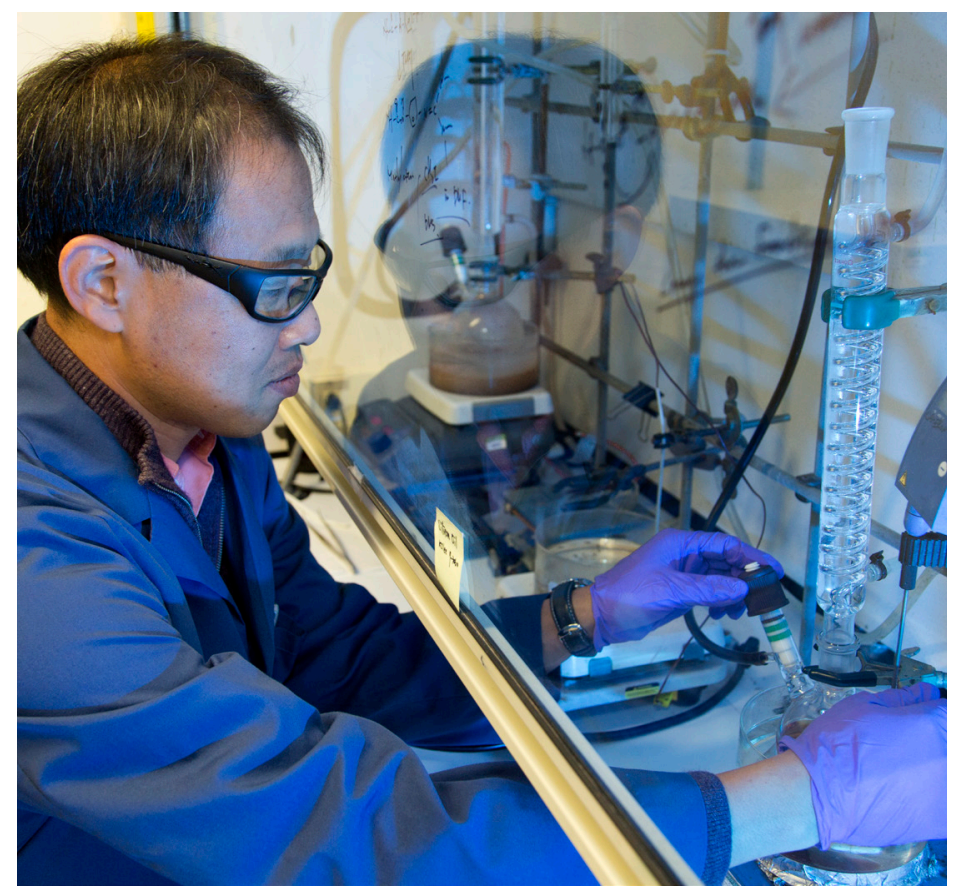

Yu Seung Kim is researching innovative methods to improve fuel cell technology.

processing; now competition to develop new materials is fierce as automakers launch the first commercially available fuel cell electric vehicles. Kim's waterless Nafion dispersion technique for building MEAs with state-of-the-art catalyst materials has produced fuel cell devices outperforming and outlasting anything commercially available, according to independently verified Los Alamos studies. The ionomer materials are more compatible with the catalyst materials, and thereby provide superior electrode performance, stability, and durability for PEM fuel cells during harsh operating conditions. "The major advantages of this MEA are durability and lifetime. This is important for its commercialization," Xu said. "There's a good chance to use these MEAs for fuel cell cars, but it's too early to say that for sure."

Kim is leading another ambitious project that has caught DOE's eye. "I want to see an alkaline fuel cell car in five years. People are doubting if it will work," he said. The chief problem: "People cannot make stable anion exchange membranes," he said, because the thin material disintegrates under high $\mathrm{pH}$ conditions. Alkaline fuel cells have been used only in power plants on NASA-crewed space flights where liquid electrolytes were used. If Kim can achieve stable alkaline membranes, which offer higher catalytic reaction efficiency than PEM fuel cells, automakers could replace expensive platinum catalysts with non-precious-metal catalysts, leading to more palatable sticker prices on the car lot. Such fuel cells also could revolutionize other energy applications like air-metal batteries, desalinations, and membranebased water electrolysis, he said. 


\section{Paul Koehler Applying nuclear physics expertise to a range of scientific challenges}

As a youngster, Paul Koehler built his own telescope and was determined to study astronomy in school. His resolve paid off. Koehler launched his career as a Los Alamos Director's postdoctoral research associate in Physics Division and developed some of the first nuclear astrophysics research at the Los Alamos Neutron Science Center (LANSCE) - the results aiding understanding of nucleosynthesis in stellar and explosive environments.

Now returned to the Laboratory after a more than 20-year hiatus, Koehler (LANSCE Weapons Physics, P-27) is diving headfirst into numerous projects that support the Laboratory's national security science mission.

For the Detector for Advanced Neutron Capture Experiments (DANCE) he is using improved neutron resonance data on neodymium and samarium isotopes to test random-matrix theory (RMT). He's leading the planning committee charged with redesigning the spallation target the Lujan Neutron Scattering Center uses to produce neutrons for basic and applied research benefitting national security, nuclear energy, and academia.

"The design is really important for getting the most 'bang' per proton," Koehler explained. "But it's a challenge-the same source has uses in nuclear physics and materials science, which have very different parameters."

Koehler is part of a team examining aging effects on nuclear weapons as part of the Neutron Diagnosed Subcritical Experiment in Nevada. He and Shea Mosby (P-27) developed the data acquisition and analysis systems for an upcoming experiment on a subcritical object at the Device Assembly Facility.

"There are so many ways he can contribute to our programs," said P-27 Acting Group Leader Aaron Couture. "That diversity is one of the reasons we brought him back."

Koehler's diversity of experience was gained at a variety of institutions, but the common threads are providing data of importance to basic and applied physics, as well as testing and improving nuclear models.

As a research scientist at Oak Ridge National Laboratory, Koehler developed expertise in neutron spectroscopy, radiation detection techniques, data acquisition hardware and software, and nuclear astrophysics. He served as a guest researcher at Norway's University of Oslo and division chief for the Air Force Technical Applications Center in Florida. From 2013 to 2014, as a LANSCE Rosen Scholar, Koehler explored new and improved experiment capabilities for weapons science and discovered significant deviations between LANSCE data and RMT.

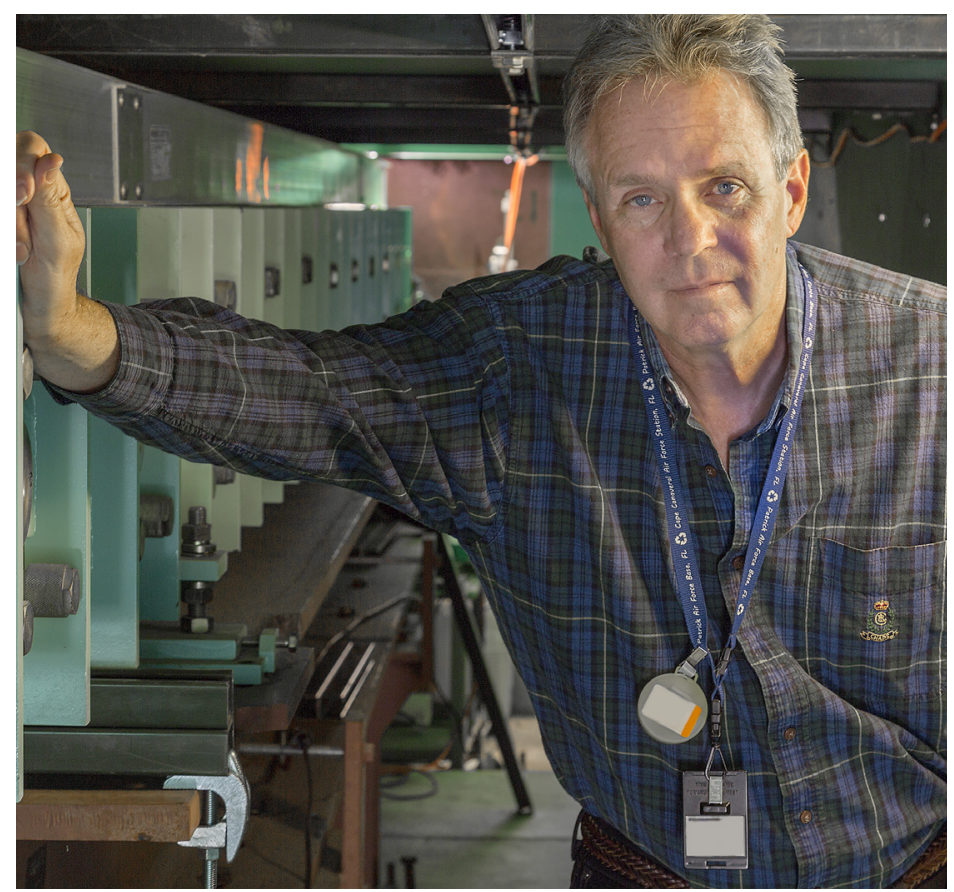

Paul Koehler inside the flight path 13 cave at the Lujan Neutron Scattering Center.

In his spare time, Koehler has been probing RMT, which underpins nuclear theories used in weapons physics and astrophysics and was first proposed about 50 years ago - and is now largely accepted. But some of the data he's collected over the years at Oak Ridge and Los Alamos tell a different story. "We have the world's best data on a number of nuclear reactions, and they don't agree with the theory. [RMT] is based on several fundamental assumptions that could very well be wrong," he said.

He's published articles challenging RMT, and subsequent researchers have posited modifications to the theory to fit the contrary data. Koehler has his own conjectures. Chief among them is resonance internal conversion, wherein a de-exciting nucleus releases energy to the atom and causes electrons around the nucleus to gain energy.

Koehler is working with theorist Toshihiko Kawano (Nuclear and Particle Physics, Astrophysics and Cosmology, T-2) to determine whether another existing model might explain the phenomenon. "The problem is, the whole idea is somewhat crazy," Koehler said. "But if it's there and everyone's ignored it for so long, it would change the way we look at everything." 
Veronica Livescu's career has taken quite a turn since she earned her master's in aerospace engineering in Romania in 1991. On her way from Bucharest to the Laboratory's Materials Science in Radiation and Dynamics Extremes group (MST-8), she changed not only countries but also disciplines, transforming herself from a mechanical engineer to a materials scientist.

The changes began as soon as she graduated. "Jobs in the aerospace industry were hard to find at that time," she said, "so for six years I worked for the Bucharest subway systema combined engineering and programming position." But Livescu wanted research opportunities and followed that desire to New York State and the University of Buffalo-SUNY, where she earned a second master's (2001), this time in biomedical engineering, working with shape-memory alloys used in novel stents for treating arterial aneurysms.

That master's work and then a job with a manufacturer of medical devices moved her to materials science and subsequently to Los Alamos.

On staff since 2005, Livescu is a member of MST-8's Dynamic Materials Properties team - a critical member, according to team leader George T. (Rusty) Gray III. "She's a gifted, passionate researcher," he said, "contributing to a spectrum of fundamental, programmatic, and exploratory research topics important to the Laboratory and broader NNSA programs."

"The team measures the static and dynamic properties of a large range of materials," said Livescu. "We're looking at the results of dynamic shock loading in metallic structures and at the influence of materials' internal structure on deformation, void nucleation and growth, and ultimate failure." She uses optical microscopy, scanning electron microscopy, and electron backscatter diffraction (EBSD) to characterize a material's microstructure - the size and crystallographic orientation of the material's grains, the interfaces between the grains, and the presence of porosity (small voids) and/or impurities.

"Every material is different," said Livescu, "and despite the fact that we understand the importance of a material's structure on its properties, we still have a lot to learn about the mechanisms involved in the generation of damage under shock-loading conditions." Detecting subtle changes in a material's microstructure can unveil critical information regarding the material's response to loading, so when possible, she focuses on using software that generates three-dimensional volumes from the EBSD analysis to create material models.

Because processing greatly influences microstructure and therefore a material's stress response, Livescu and her colleagues have recently chosen two kinds of samples to work with, some that were traditionally manufactured-wrought and annealed-and others that were created by additive manufacturing, in which powdered metal is melted as it gets

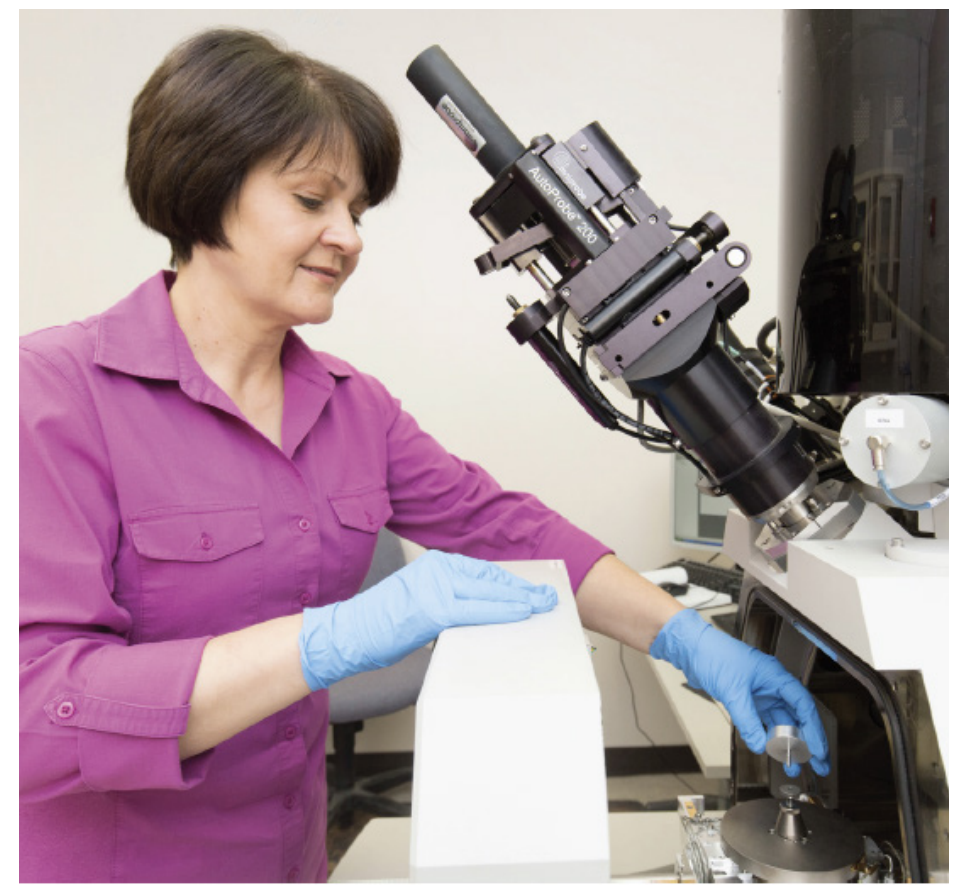

In Los Alamos's Electron Microscopy Laboratory, Veronica Livescu analyzes a range of materials' properties, with the ultimate goal of creating materials designed for a specific function.

deposited in ultrathin layers. The microstructure of the two, she said, is quite different. "The additively manufactured materials have a much finer grained, more complex microstructure, exotic and challenging at the same time. In addition to the polycrystalline microstructure, the layer-by-layer deposition results in a macroscale pattern, which looks almost like rows of fish scales."

Livescu analyzes the samples both before and after the shock-loading experiments, many of which she and the team do themselves, using a gas gun and split Hopkinson pressure bar for one-dimensional shocks and mechanical frames for the slow, steady pressure of quasistatic loading. "In addition," she said, "I study samples that were tested using high explosives, which lets me tap into the effect of three-dimensional complex loading. I get those samples by collaborating with people from other divisions."

Collaboration is the reason for the efforts of Livescu and the team. Their work supports Theoretical Division's development of models and simulations to better predict how materials behave under extreme conditions. The work is important to stockpile stewardship and is one of DOE's scientific grand challenges.

Livescu said she never expected to do such work back in 1991, before she started down the path to her current job. "I never in my life thought that I would work for Los Alamos National Laboratory, but I saw opportunities and took them. It all turned into something great."

Originally published June 2016 


\section{Nathan Mara Bulking up lightweight nanomaterials}

When Nathan Mara, who works toward making damage tolerant materials Los Alamos National Laboratory, tells his four children he is inventing an Iron Man suit, they beg to see it. Yet designing a finished good like a superhero's outfit is a considerable feat due to the complexity of nanomaterials, which create its unique attributes.

Mara (Center for Integrated Nanotechnologies, MPA-CINT) is known in his field for bulking up nanolayered composites. Through the Lightweight Materials Consortium, sponsored by DOE's Vehicle Technologies Office, American industries can tap into Mara's expertise, including his techniques for damage-tolerant layered nanocomposite bulk fabrication.

Increasing materials in size from the nanoscale to the bulk scale is the hardest part, Mara explained. In his office, he removed from a plastic vacuum chamber a thin foil made of 1,000 layers of copper. The material exhibited "indestructible Iron Man suit kind of properties," Mara said, "as strong as the strongest tool steels and healing itself under ion irradiation conditions." He was unable, however, to fabricate quantities bigger than a button with those desirable attributes.

Since that experiment, his research has revealed that manufacturing methods can change a material's behavior just as much-and sometimes more than-its combination of elements. He chose materials science and engineering for his doctorate at the University of California, Davis, after a double bachelors in mechanical engineering and materials science and engineering because he likes "seeing everything from materials design to engineering design come together into an impactful story," he said, and that requires a grasp of both disciplines.

Mara and his colleagues are determined to show that magnesium, one of the lowest density structural materials on earth, can be made robust enough to replace some components in cars - with the weight savings boosting gas mileage from 30 to 76 miles per gallon.

The challenge is to transform magnesium from coarsegrained to nano-grained, which results in a far stronger material. Through the Laboratory's internal research and development program, Mara and colleagues have set a target of producing nano-magnesium composites in bulk sheet form in three years. Such a breakthrough in "microstructural processing by design," he said, would transform magnesium research and manufacturing. He's banking on interface driven properties, his area of study into the material qualities created by the interplay of atoms between constituents of composite materials, to guide the way.

When Mara and Los Alamos theorist Irene Beyerlein (Fluid Dynamics and Solid Mechanics, T-3) began their research in 2008, few teams were synthesizing multilayered nanocomposites in bulk sizes.

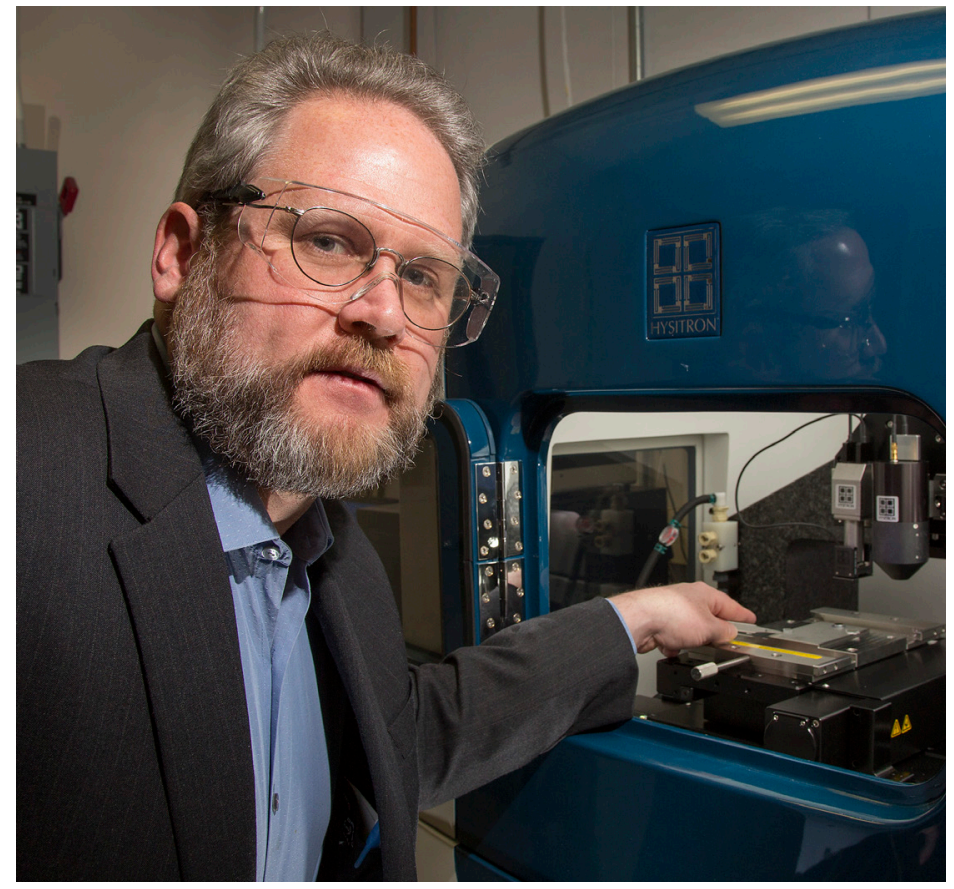

Nathan Mara designs materials with specific properties by manipulating and controlling atoms one by one at the nanoscale-and using novel nanomanufacturing processes.

With an ancient steel-making technique for forging samurai swords as their inspiration, they slashed and smashed two soft, ductile metals-copper and niobium-into extremely thin layers-down to 40 atoms across to dramatically enhance the properties of such materials. The result was a sample as big as a snow ski and as ultrahigh strength, thermally stable, and radiation resistant as an Iron Man suit. Through subsequent experiment and modeling, they saw how the manufacturing process caused the atoms where the two metals met - the interface of copper and niobium - to fall into an unusual arrangement, and thus create the material's proper ties, rather than the constituent metals themselves.

As Mara spoke, he picked up a copper-niobium sample about the size of a chocolate bar, but thicker and heavier, with "65,536 layers" written across it.

How do a material's interfaces form this way? Mara said if he could watch the process unfold in picosecond time scales and at nanometer length scales, such as will be possible at Los Alamos's proposed MaRIE (Matter-Radiation Interactions in Extremes) experimental facility, he could find out.

He looks forward to the day when he can drive up in a lightweight nanocomposite sports car and step out to show his children his impenetrable armor suit. Until then, he will just drive his kids around town in his ' 89 Chevy van. 
"Reinvigorating" is how Physics Division Leader David Meyerhofer described the opportunity to learn new physics - the kind performed in one of Los Alamos National Laboratory's three original technical divisions.

"What attracted me to Los Alamos, and the Physics Division in particular, was the breadth of physics done in the division," said Meyerhofer, who after 14 years as experimental division director of the University of Rochester's Laboratory for Laser Energetics (LLE) (and 28 years at the university), was "fundamentally" ready for something different.

Since arriving in August, he has set for himself the challenge of understanding the physics in each of the division's 25 teams "so I can be an advocate for each of them." To aid that endeavor, Meyerhofer is meeting with research teams in their experimental areas. "Physics Division has a lot of really bright people, a lot of enthusiastic people," he said.

Developing new challenges to engage them is central to how Meyerhofer sees his role as division leader. "I want to ensure a professional and collegial work environment, one encompassing collaboration across the division to develop new opportunities," he said.

One way he is doing that is by connecting people and raising awareness of capabilities, to prevent the "missed opportunities" that occur when researchers are unaware of each other's work. "Finding ways to get broader communication both within the Physics Division and with the other divisions at Los Alamos is something I continue to work on," he said.

A committed effort to envisioning the Physics Division of the future, through strategic planning on the part of staff and management, is another way. "We need to be looking out 5-10 years - what do we want the Physics Division to look like, what do we want to and should be doing-and put the planning in place to make it happen," he said.

The work of a national security science laboratory is not new to Meyerhofer, who has a $\mathrm{PhD}$ in plasma physics from Princeton University. As former member and chair of the Predictive Science Panel, he worked with Livermore and Los Alamos national laboratories' predictive weapons physics programs. At LLE he was point-of-contact for the nonignition aspects of stockpile stewardship research for the Inertial Confinement Program.

Meyerhofer became interested in energy research as an undergraduate physics student at Cornell University shortly after the 1970s U.S. gas crisis. A summer job at the Princeton Plasma Physics Laboratory introduced him to spheromaks, a particular form of plasma configuration, and to some of his now Los Alamos colleagues. Scientific highlights included early work on high-field atomic physics and high-energy

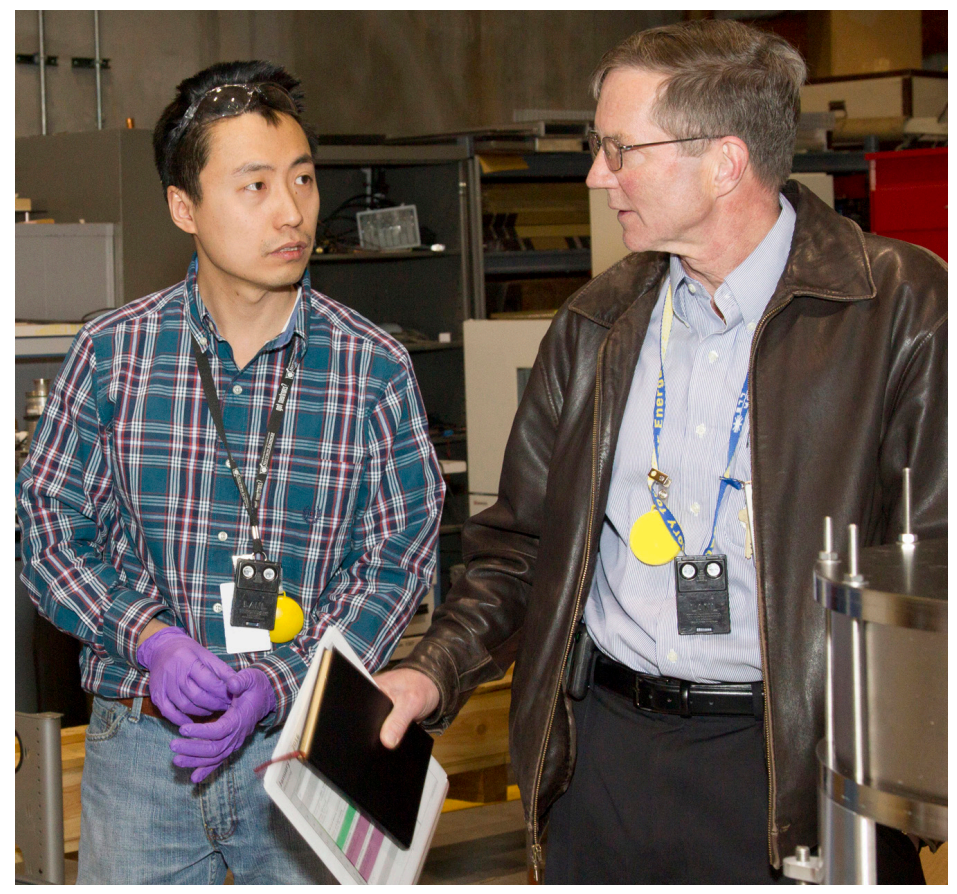

David Meyerhofer (right) and Zhaowen Tang discuss R\&D for the Los Alamos neutron electric dipole moment experiment at the Los Alamos Neutron Science Center.

physics experiments at SLAC National Accelerator Laboratory that produced electron-positron pairs from a vacuum.

In welcoming him to the Experimental Physical Sciences Directorate, Associate Director Mary Hockaday said Meyerhofer "has a demonstrated ability to develop synergies between weapons and basic science, and to promote research activities that deliver on mission while enabling scientific creativity."

For example, while at LLE, he worked on developing the science case for a new laser system that allowed scientists to expand the scope of their research. The addition of a new capability, the OMEGA EP, was the result of user input gleaned during a workshop series, "which allowed people to think about the different kind of physics they could do beyond the OMEGA laser system," he said.

To early-career Physics researchers looking to make an impact, Meyerhofer said, "You need to take the opportunity to learn what other people in this division are doing." To staff who are familiar with the status quo, he said, "Ask the question why we've done something this way forever-is this the optimal way to do this?"

The aim, he said, is "a culture where everyone is heard, where we get new ideas, and it's not just business as usual."

It's a principle Meyerhofer himself follows: "I like to say my door is always open." 


\section{Andy Nelson Bolstering worldwide nuclear fuels research}

Even before workers began removing more than 1,000 fuel rods from Japan's damaged Fukushima nuclear power plant, the country's scientists were running crucial experiments at Los Alamos's Fuels Research Laboratory (FRL), seeking to simulate and study the atypical oxide fuel reaction conditions resulting from the 2011 incident.

"The hope is that we both benefit," said Andy Nelson, who participates in and oversees the experiments as well as supervises the FRL's operations. Oxide fuel is also used in United States nuclear power plants.

The experiments were made possible by a 2013 bilateral agreement between Japan and the United States to coordinate nuclear research. Each Japan Atomic Energy Agency researcher spends a year at the $\mathrm{FRL}$, pursuing mutually agreed upon projects using the lab's powerful suite of tools. The third Japanese scientist arrived last spring. The visits are a more efficient means of obtaining valuable and timely data than Japan constructing a similar facility, Nelson said.

The Department of Energy Office of Nuclear Energy (DOE$\mathrm{NE}$ ) funded construction of the FRL for the study of existing and development of new nuclear fuels.

The Fukushima incident was "a big realization about what we don't understand about light water nuclear reactors," which are in use around the world, Nelson said. With FRL data, researchers contribute to improved predictions of radioactive fallout in off-normal situations, leading to a science-based decision-making approach about how to respond, such as deploying work crews or evacuating communities or cleaning up the damage, he said.

In 2011, the Laboratory recognized Nelson (Engineered Materials, MST-7) with an internal award for managing the start-up of radiological work at the FRL, a complex feat for a facility open to national and international scientists, postdoctoral researchers, and students: 20 percent of DOE-NE's budget is allotted for university research. Nelson said he is passionate about keeping the FRL "dynamic and flexible" for a variety of actinide research, with quick access to its capabilities.

The lab provides a "specialized set of fuel synthesis and characterization capabilities that is unique in the United States," said Kenneth McClellan (Materials Science in Radiation and Dynamics Extremes, MST-8). Nelson and his team "support and enable development of uranium- and thoriumbased nuclear fuel systems, which is especially relevant as, for the first time in many years, the nuclear community looks to develop new and safer fuels for commercial power generation and for smaller-scale, special purpose reactors."

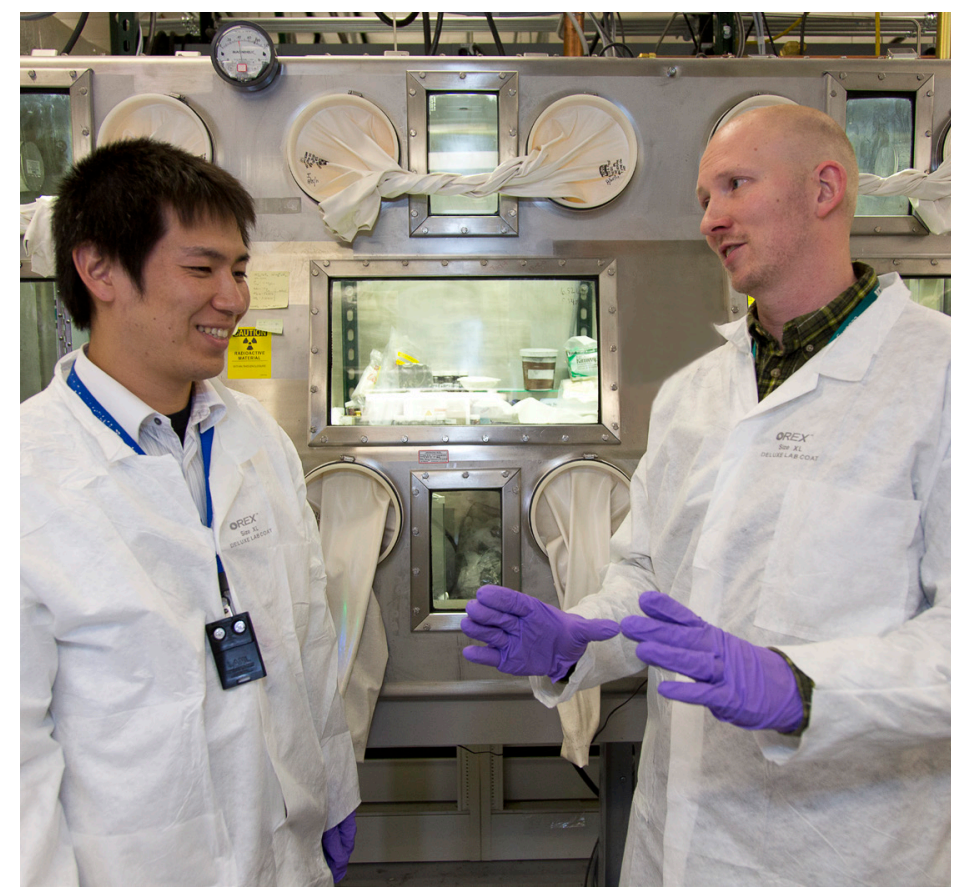

Andy Nelson (right) and year-long Japanese visiting scientist Shun Hirooka measure thermophysical properties of uraniumbased fuels and assess fabrication processes at Los Alamos National Laboratory's Fuels Research Laboratory. The lab is supported by DOE's Office of Nuclear Energy and the National Nuclear Security Administration.

Nelson screens and monitors all experiments, consulting with materials and safety experts before launching projects that can employ a range of equipment-lasers, gases, and powerful electrical sources, as well as radioactive materials.

He began guiding this meaningful work two years after earning his doctorate in nuclear engineering and engineering physics. "I love what I'm doing," said Nelson, who recalled as a toddler being fascinated watching molten metal solidify in the shop where his father taught high school welding.

Switching his college studies from engineering mechanics to nuclear engineering gave Nelson, who initially considered becoming an aerospace engineer, a wide breadth of knowledge when he finished his $\mathrm{PhD}$ in 2009-and his diverse skill set equips him to adapt to customer needs.

McClellan, his mentor, said Nelson was "the natural choice to take over the FRL as it started up ... As a postdoc working on the Fuel Cycle R\&D program, Andy had personified the special skill set required for success in advanced fuels research, namely, the ability to integrate the design and performance requirements from a nuclear engineering perspective (his degree) along with the understanding of the chemistry/process/structure/performance relationships (materials science) that control fuel performance." 
In a dark laser lab filled with shiny tabletop equipment, scientist George Rodriguez explained how he designs and builds small-scale instruments to probe the properties of everything from human DNA to subcritical nuclear explosions. During his 22-year career at Los Alamos National Laboratory, he has had countless successes, most related to fundamental materials science.

The story he tells today, however, is of applied research. Rodriguez is committing his signature creativity and ingenuity to one of the Laboratory's most pressing challenges-getting precise experimental data for the sake of refining codes used to predict nuclear weapons performance and longevity.

Rodriguez helped develop an advanced fiber optic probe sensor for studying materials in extremes by merging two existing technologies, pitched it to Physics Division, and found himself part of an 800-member team conducting subcritical weapons experiments at the Nevada National Security Site. For that work, he was honored with a 2014 Department of Energy Defense Program Award of Excellence as part of the Gemini Experimental Series team.

For his leadership in the development and application of ultrafast laser-based and high-speed optical diagnostics for myriad applications over the course of his career, he was named a 2014 American Physical Society Fellow.

He is a member of the Center for Integrated Nanotechnologies' Laboratory for Ultrafast Materials and Optical Science (LUMOS) team, which uses ultrashort-pulse lasers and other instruments to gain material physics insights. LUMOS, which operates four laser labs at Technical Area-35, also custom-makes high-speed diagnostics for researchers.

Rodriguez devised an instrument that measures both velocity and pressure smack-dab in the middle of shocks and high explosive blasts. This fiber Bragg grating (FBG) sensor shoots light along a string of glass and bounces it off an optical grating-based sensor - a safer approach than conventional electrical switches, which require high voltage near explosives. The light source, FBG sensor, and sensor detection system fit on a rack the size of two dorm refrigerators and can be shipped to various locations. When the equipment travels to Nevada, so does Rodriguez, providing technical guidance during week-long underground tests and interpreting results in a Laboratory report for the weapons programs.

"It's a neat technology," said Mike Furlanetto, head of diagnostics for the high-priority Gemini plutonium experiments. Instead of measuring only at specific times, the fiber optic probe continuously measures the high explosive burn from different locations in the device, capturing subtle changes in energy flow that the standard method could miss. "Having more elaborate data may help the Weapons Physics divi-

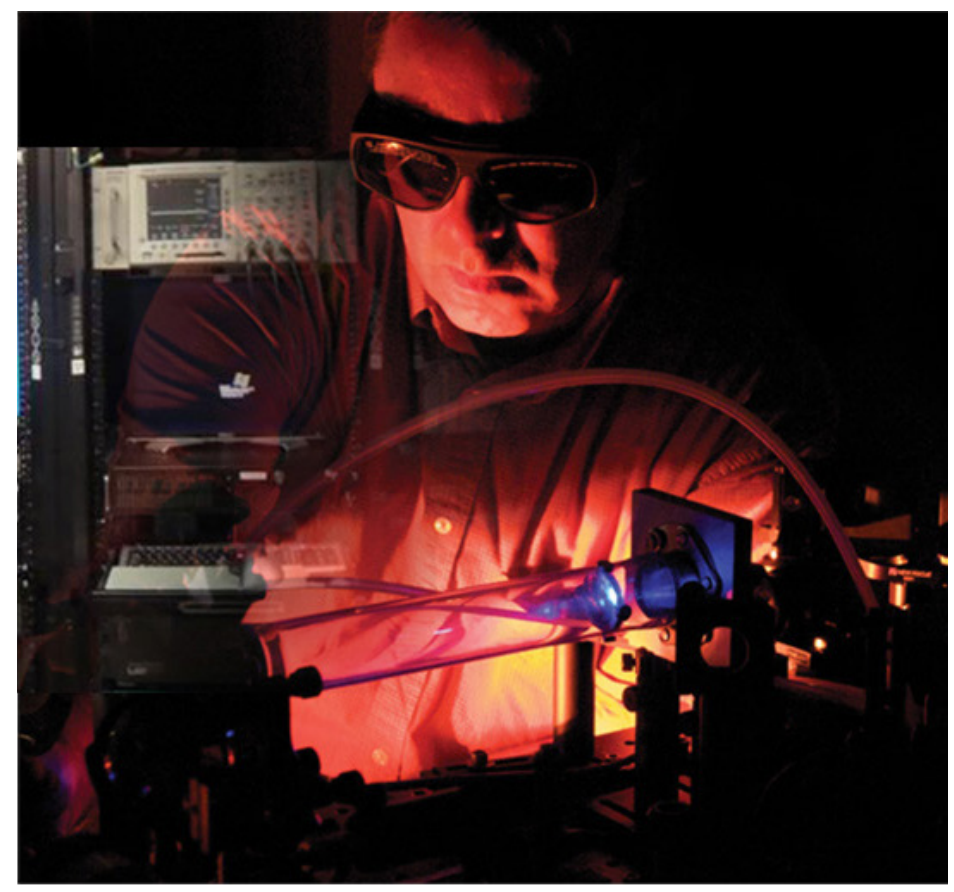

George Rodriguez, shown in a LUMOS laser lab, developed a fiber optic probe sensor for the Gemini project that has changed how Los Alamos does early-time hydrodynamic experiments. The sensor measures the changing energy flow in high explosives used in subcritical experiments.

sions narrow down which parts of physics are deficient in plutonium performance models," he said, noting the sometimes vexing disconnect between experimental data and computer modeling results.

When not supporting experiments at the Nevada site or at the Los Alamos Dual Axis Hydrodynamic Radiographic Test Facility, where the sensor is being integrated into routine diagnostics for hydrodynamic tests, Rodriguez is developing the next version, which relies on ultrafast, short-pulse lasers to parse the effects of pressure and temperature from a single FBG sensor. Chemistry Division, as well as the weapons program, needs these readings for different applications that require measurements of materials in extreme conditions.

He also taps his laser expertise while drawing designs for the laser photoinjector of the MaRIE Injector Test Stand, part of the Matter-Radiation Interactions in Extremes (MaRIE) $x$ ray free electron laser. The FBG sensor is an example of the diagnostic development science of materials in extremes on the roadmap to MaRIE, the Laboratory's proposed experimental facility for time-dependent studies at the mesoscale.

Rodriguez, who earned his PhD from the University of llinois at Urbana-Champaign, learned early to diversify. "You find the opportunity space (at the Laboratory) is a lot bigger if you are willing to go out in other groups and divisions and make connections," he said.

Originally published March 2015 


\section{Filip Ronning Pursuing materials studies that push the scientific agenda}

Physicist Filip Ronning (Condensed Matter and Magnet Science, MPA-CMMS) makes electrons nervous, specifically, the f-electrons of the actinides and lanthanides. Ronning is part of a DOE Basic Energy Sciences (BES) project that focuses on the f-elements and their electrons in a search for new materials that can reveal new physics. The project team -6 staff members, including Ronning and 5 postdoctoral researchers - finds about 20 new materials a year.

The f-elements hover between being magnetic and nonmagnetic, so the BES team designs compounds and experiments that present the f-elements' electrons with a magnetic dilemma. "We're trying to make the f-electron uncomfortable," said Ronning, "unable to decide what it wants to do. Does it want to be magnetic and stay in place, or nonmagnetic and itinerant, freely roaming throughout the solid?"

It's in that uncomfortable place that new states of matter may emerge. To see if that will happen, the team tests a constantly changing selection of new materials in the form of crystals created from an f-element mixed with elements from other parts of the Periodic Table. The crystals are cooled by liquid helium in a cryostat and their properties measured as a function of temperature, magnetic field, and pressure.

The BES project has been ongoing at the Laboratory since the 1980s. Many groups have similar interests. But Los Alamos is one of the few groups working with the f-elements, which are a strength here because of the Lab's historical interest in plutonium, along with the other actinides and by commonality, the lanthanides.

The f-elements also star in Ronning's other project, an LDRD Directed Research study for which he is principal investigator. The project team - nine staff members and a handful of postdocs - studies topological materials, topology being a new way of classifying materials. "It's a very hot field," said Ronning. So hot in fact, that the 2016 Nobel Prize in Physics was just awarded to three British researchers for their groundbreaking work in topological phase transitions and topological phases of matter. "It's wonderful to have the Nobel committee recognize both the foundational works of these great scientists and the exciting new field of study that they have enabled."

Topological materials are classified according to discrete values determined by the material's electronic structure. A mathematical analogy exists to the geometric classification in which the number of holes an object possesses defines the object's topology. For example, a coffee cup and a donut are topologically equivalent because each has one hole. Beyond classification, the presence of a figurative "hole" in a material's electronic structure guarantees certain physical responses in the material.

Ronning's team tests samples made from f-elements to see if the magnetism associated with f-electrons affects the topol-

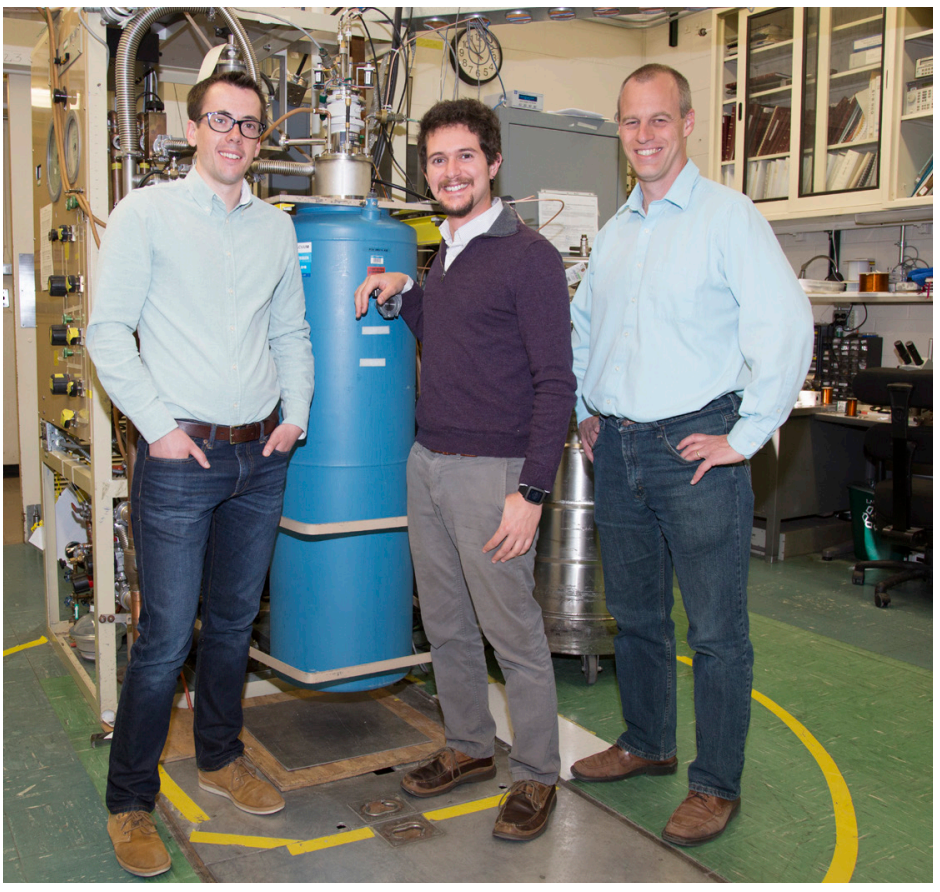

Filip Ronning (right) in the low temperature nuclear magnetic resonance lab with postdoctoral researchers Nick Wakeham (left) and Adam Dioguardi (center).

ogy. If it does, researchers could potentially discover novel states of matter with unique properties, opening the door to new materials with applications for sensing, electronics, and computing.

Ronning earned his physics doctorate at Stanford University in 2001 and did postdoctoral studies at the University of Toronto. He came to Los Alamos in 2003 as a Director's Postdoctoral Fellow and was a Reines Distinguished Postdoctoral Fellow before becoming a staff member in 2006. He has coauthored more than 200 publications, including in Science, Nature, and Physical Review Letters. He is a Fellow of the American Physical Society. Ronning has earned the respect of his group and the international scientific community according to Laboratory Fellow Joe Thompson, who has led the BES project for more than 20 years. Thompson will be turning the lead over to Ronning in fiscal year 2017.

He is also greatly appreciated by the postdocs he directs, as evidenced by his 2015 Laboratory Postdoctoral Distinguished Mentor Award. "Filip's genuine interest in the career development of his postdocs goes well beyond what might normally be expected," said Nicholas Wakeham, who finished his postdoctoral studies in April. "He valued my need to develop as a scientist on an equal footing with the need for CMMS to produce world-class work."

Some of the postdocs who have worked with Ronning have become staff members. Others have taken positions in the United States or Asia and Europe, but they've stayed in touch. Said Ronning, "They are some of our strongest collaborators." 


\section{Brian Scott Providing materials synthesis, characterization for national security needs}

Making gunpowder for backyard experiments was one of Brian Scott's favorite pastimes as a youngster in Idaho. In those days, potassium nitrate, a key ingredient, could be purchased at the pharmacy, and his father was supportive of his hobby.

Now, he's a chemist (Materials Synthesis and Integrated Devices, MPA-11) working with materials few people can. The Lab's national security programs, as well as the Atomic Weapons Establishment and Lawrence Livermore National Laboratory, look to Scott to make thin films coated with radioactive materials, which are important for materials aging studies as the United States and the United Kingdom modernize their nuclear weapons.

Demand for Scott's expertise soared as researchers worldwide heard about polymer-assisted deposition (PAD), a Los Alamos-developed method for making thin films. PAD has opened the door for new experiments because a small amount of radioactive material, like 25 micrograms, is sufficient. More facilities can accept the samples because the plutonium is non-dispersible, and the risk of radioactive release is low.

Quanxi Jia (Center for Integrated Nanotechnologies, MPACINT) invented PAD for non-radioactive materials, and Laboratory researchers Tony Burrell and Mark McCleskey adapted PAD to make uranium dioxide and triuranium octoxide, with Scott characterizing the films' structures using x-ray diffraction. Soon, Scott took over the Lab's PAD capability for actinides.

Offering easy setup and low cost, PAD involves dissolving the actinide of choice in a polymer, spin coating a thin film with the solution, baking the film, and measuring the crystallographic structure. "Making new materials and characterizing them, and then using them to figure out some of these national security problems is rewarding to me," Scott said.

For the first time researchers are creating fissions in a cubicphase plutonium dioxide film, using cold neutrons at the Los Alamos Neutron Science Center. As pieces of plutonium dioxide fly off the one-inch round film, the plutonium dioxide crystal structure is altered. These structural changes are key to understanding aging mechanisms in materials, which may cause changes in behavior. The findings are relevant to nuclear weapons, nuclear forensics, and nuclear power.

When the U.S. Department of Homeland Security asked Los Alamos to see how chemical signatures could enhance analyses in nuclear forensics, principal investigator Marianne Wilkerson (Nuclear and Radiochemistry, C-NR) enlisted Scott. His expertise in powder $\mathrm{x}$-ray diffraction and thin films was vital, but from past collaborations, she knew Scott

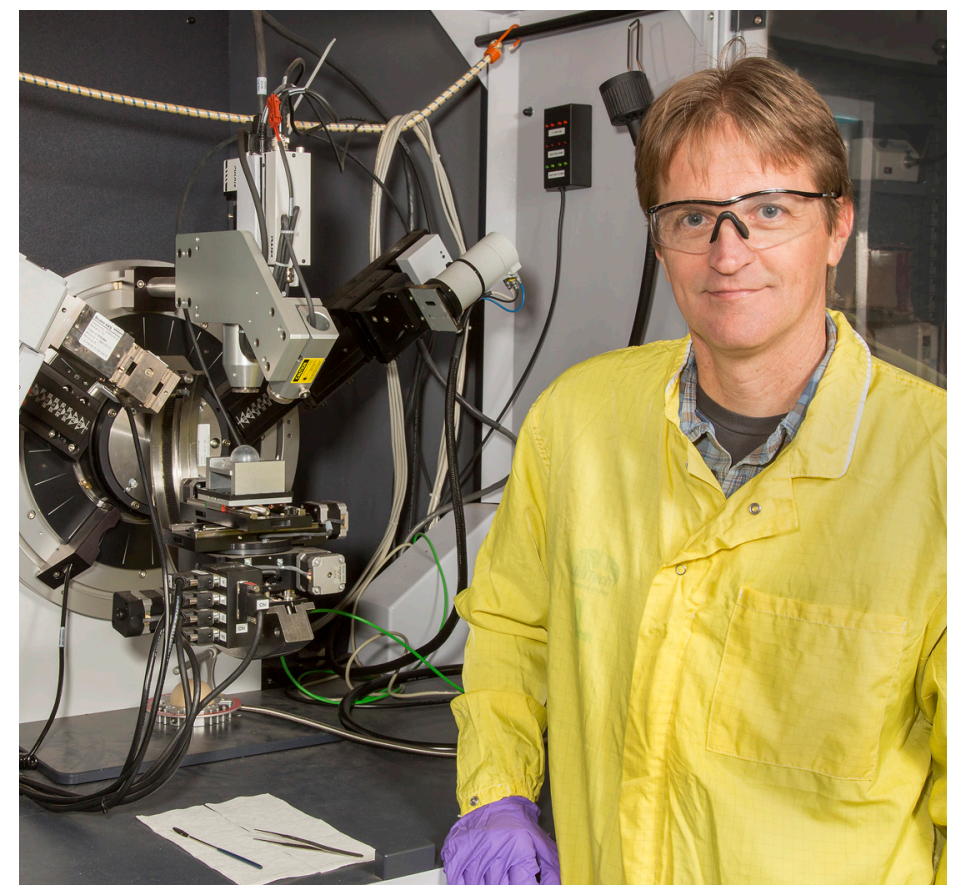

Loaded with a plutonium sample, this $\mathrm{x}$-ray diffractometer at Los Alamos is a rare capability allowing chemist Brian Scott and his MPA-11 team to analyze radioactive materials for national security research.

would offer new experimental approaches and broader interpretations across the project's measurements and data. In particular, PAD plutonium dioxide materials provided a useful approach for initiating experiments with plutonium. This team is studying the actinide's reactivity under controlled conditions of temperature and humidity. Every few months they examine the stored samples, looking for changes in structure using a suite of spectroscopic techniques. As observed with uranium oxide powders, the chemical signatures of plutonium oxide materials could provide clues as to how the material was made and where it was stored. The research is promising and ongoing.

After completing his $\mathrm{PhD}$ in physical chemistry from Washington State University in 1990, Scott began his career as a Los Alamos postdoctoral researcher fascinated by the natural symmetry of crystal structure. He spends half his time performing basic research on materials synthesized across the Lab and has authored more than 380 papers with 8,000 citations. In 2004, the Lab honored him with a Distinguished Performance Award for creating an x-ray diffraction and molecular modeling capability.

Scott said he was drawn to a career in chemistry because it's a hands-on way to solve practical problems, but he never imagined how significant his work could be to the nation and its allies. "Where the world is headed, and what the world has become-working on those problems has become more and more important," he said. 


\section{Sigma Division staff}

\section{Beverly Aikin named 2016 ASM Fellow}

ASM International named Beverly Aikin to its 2016 class of Fellows. Recipients of one of the highest honors in the field of materials, ASM Fellows are technical and professional leaders who have been recognized by their colleagues and serve as advisors to the Society.

Aikin was cited for "advancing microstructure, property, processing relationships in metals and intermetallics; enhancing the safe handling, security and recycling of beryllium; and for

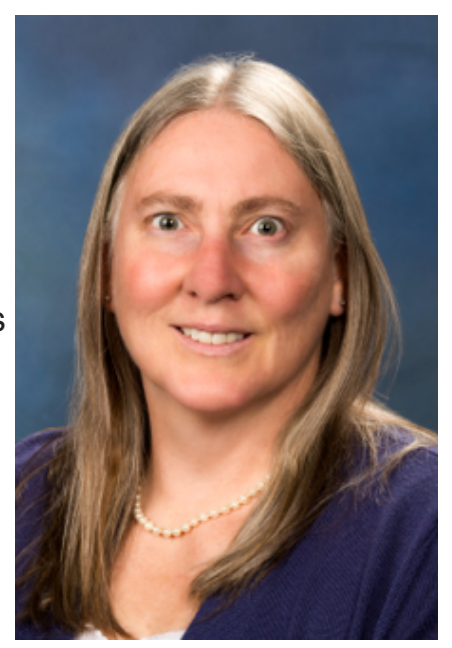
her commitment to K-12 student outreach in STEM."

She holds a doctorate in materials science and engineering from the University of Virginia. She is an R\&D engineer on Sigma's forming and machining team, maintaining beryllium and hot isostatic processing capabilities in the Beryllium Technology Facility for weapons, global security, nuclear fuels, and other Los Alamos research programs. She has been a volunteer for the Los Alamos chapter of ASM since 2003, serving on its executive board. Aikin founded and supports the annual Discovery E Engineers Week event in the county.

ASM International serves the materials science and engineering profession and has a global network of 36,000 members. It provides authoritative information and knowledge on materials and processes, from the structural to the nanoscale.

\section{Jesse Martinez recognized with Distinguished Performance Award}

Jesse Martinez is the recipient of a Laboratory Distinguished Performance Award as part of large-team effort to manufacture a power supply live unit to support Baseline Design Review. With a deadline two years ahead of the productrealization schedule, the team recreated a defenserelated power supply using plutonium-238 oxide in just six months, in time for a baseline design review.

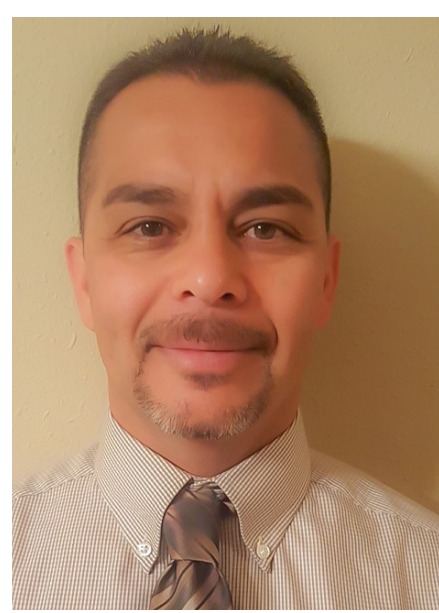

The power supply, a request of the National Nuclear Security Administration and Sandia National Laboratories, had not been made at Los Alamos, or anywhere else, since the 1980 s, but this team, collaborating with Kansas City and Sandia, manufactured and tested six live units and had them ready two weeks before the baseline design Review. They accomplished this important task through focus, dedication, and long hours of work, displaying a "can-do" approach that made success possible.

\section{Chris Chen granted patent for granulation of fine, radioactive powder}

\section{A process invented by Chris Chen for granulating fine powder containing radioactive materials was recently granted U.S. Patent No. 9,409,825 B2.}

Wet and dry pressing are common for compacting fine powder, and help prepare products ranging from medicinal pellets to magnetic and dielectric ceramics, engineering ceramics, refractories, and nuclear fuel rods. Current standard practice is to add organic additives such as binders and plasticiz-

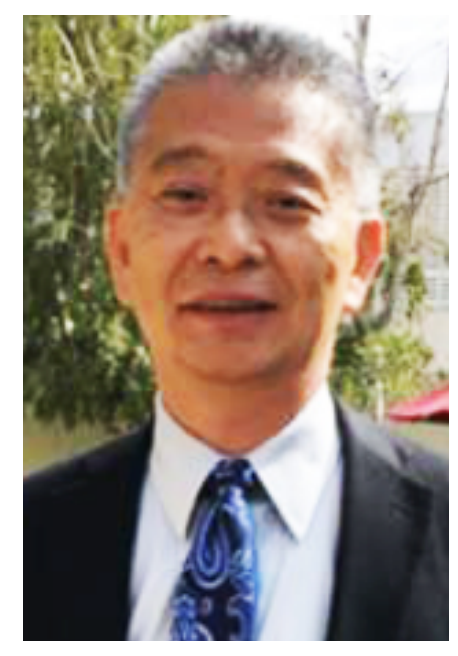
ers to this granulated powder, where they serve as a deformable medium and are believed to play a role in retaining the granule's shape and structure. Such granulated powders may be needed for applications such as in nuclear fuel, but exposure to radiation causes their additives to break down quickly.

Chen's novel process forms a first-green-body from a fine powder that has radioactive powder. The weak, first-greenbody is strengthened by high-temperature heat treating. It is then granulated by crushing or milling followed by sieving, thereby creating a granulated radioactive powder that may have a desired granule size distribution without the usual organic binders. The product relies on the thermal bonding among the fine powders to maintain its shape and structure, and is still able to flow easily into a die press.

The work, sponsored by Thor Energy of Norway under agreement number FIA-09-034, supports the Laboratory's Energy Security Solutions mission area and Materials for the Future science pillar and by creating a product that could be leveraged for nuclear fuel applications, among other areas. 


\section{Sigma machinists, welders, metallographers}

\section{Contributing vital expertise in effort to produce cancer-fighting isotopes}

Los Alamos, Brookhaven, and Oak Ridge national laboratories are developing a large-scale accelerator production capability for actinium-225 (Ac-225), a rare radioactive isotope that attacks cancer cells without damaging nearby healthy cells. Using the unique capabilities available only in the Sigma Complex at Los Alamos, Sigma Division researchers have produced encapsulated thorium target assemblies that meet the exacting specifications required to produce Ac-225 via irradiation using high-energy proton beams at accelerator facilities located at Brookhaven and Los Alamos labs. Irradiated targets are shipped to Oak Ridge for chemical processing, with distribution of isolated Ac-225 for initial evaluation studies conducted by independent researchers and clinicians worldwide.

This tri-lab effort is driven by the pressing need to provide enough Ac-225 to support clinical trials of medicines based on this isotope. The current supply of Ac-225 available to the research and commercial market is inadequate. The tri-lab team, through the auspices of DOE's National Isotope Program, is developing chemical processing techniques and production-scale targetry to prepare for Ac-225 manufacturing.

None of this would be possible without the capability to manufacture encapsulated thorium capsules for irradiation. The Sigma Complex at Los Alamos is the only place in the United States with the equipment, expertise, and access for melting, forming, and machining thorium, which is radioactive. The Isotope Program has collected a ready supply of thorium at Los Alamos for the effort.

Over the past two years, Sigma Division has produced 11 thorium targets for the Los Alamos Isotope Production Facility, where researchers test the capsules to ensure their viability during irradiation and measure the Ac-225 yield to address the increasing worldwide clinical demand. The Los Alamos Neutron Science Center is one of the nation's most powerful proton linear accelerators, providing protons at 100 $\mathrm{MeV}$ to the Isotope Production Facility for the purpose of large-scale generation of radionuclides needed by the larger isotope community.

Sigma machinists, welders, and metallographers have manufactured three extremely thin thorium irradiation targets for Brookhaven National Laboratory. The fabrication of these targets presented new challenges and required exceptional skill and precision to meet Brookhaven's specifications for 0.015 -inch-thick thorium targets in a capsule with a 0.020 -inch-thick window. Jeff Scott rolled existing thorium plate to the 0.015-inch-thick dimension, and machinist Jeff Robison machined the thorium target pieces. Rick Hudson machined the thin Inconel capsule halves, which Matt Dvornak electron beam welded together with the thorium

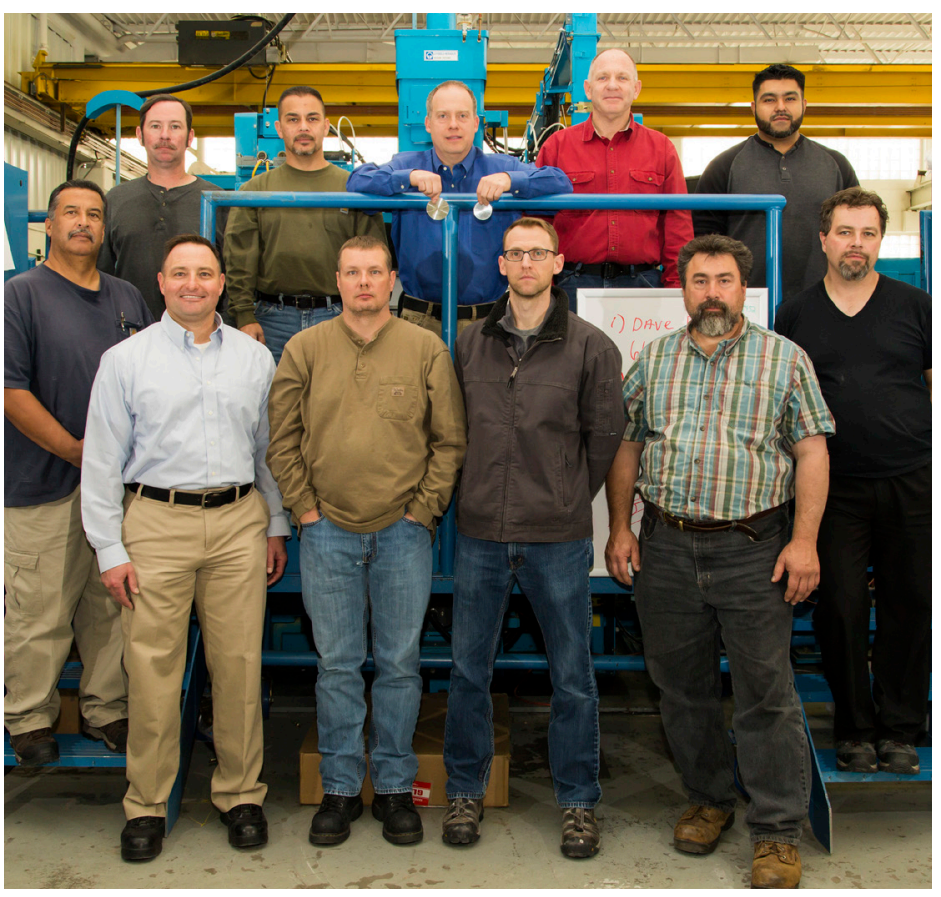

Members of the Sigma team include, left to right, (front) Daniel Javernick, Richard Hudson, Hunter Swenson, and John Bernal; (back) Victor Vargas, Andrew Duffield, Jesse Martinez, Jason Cooley, Robert Forsyth, Joel Montalvo, and Bo Folks.

inside. The welding test specimen contained a 0.015 -inchthick stainless steel disk to mimic the thorium target. After welding, a hole was bored into the test specimen's center for helium leak testing. The test confirmed that the target did not leak. These targets will be irradiated at the Brookhaven Linac Isotope Producer in support of ongoing Ac-225 product evaluation studies.

As Los Alamos established a versatile thorium target manufacturing capability, the following Sigma staff have been instrumental over the past two years: Richard W. Hudson, Andrew N. Duffield (now with MET-2, Pit Integrated Technologies), Matthew J. Dvornak, Jesse N. Martinez, Matthew T. Strandy, Joel D. Montalvo, Bo S. Folks, Jeffrey C. Robison, Tim V. Beard, Victor D. Vargas, Maria I. Pena, Hunter Swenson, Daniel A. Aragon (now with Prototype FabricationWeapon Fabrication Services), Jeffrey E. Scott, Kester D. Clarke, Robert T. Forsyth, Daniel A. Javernick, James C. Foley, and Jason C. Cooley.

This work was supported by the United States Department of Energy, Office of Science via funding from the Isotope Development and Production for Research and Applications subprogram in the Office of Nuclear Physics. This new capability at Sigma supports the Lab's national security mission and Materials for the Future science pillar. 


\section{Alice Smith Detecting plutonium's secrets using neutrons and $x$-ray diffraction}

By age 8, Alice Smith had discovered the joy of playing with microscopes and other instruments in her father's university hospital genetics laboratory. "I didn't make him very happy because I was messing up everything, but it paid off in the end," she said.

Given strong support from her physician father and electrical engineer mother, Smith said her path was set in eighth grade when she was accepted into an elite Romanian high school dedicated to math and science. At Louisiana State University she earned her $\mathrm{PhD}$ in physics and developed a passion for running synchrotron experiments and working with neutrons.

Ten years ago, as a postdoctoral researcher, she was drawn to the Lujan Neutron Scattering Center at Los Alamos to learn new experimental techniques using neutrons. Now a staff scientist in Nuclear Materials Science (MST-16), Smith performs studies of actinides, a series of radioactive metallic elements, for the Laboratory's fundamental science and nuclear weapons missions. She is the group's instrument scientist for X-ray diffraction and has mastered other techniques. "Science remains my main focus," she said. "Changing the type of materials makes it more interesting; the same for changing techniques."

In 2012 the National Nuclear Security Administration gave Smith a Certificate of Appreciation for her role in making new plutonium pits for W88 warheads. Using x-ray diffraction, she and technician Fritz Sandoval (MST-16) tested the structural character of each pit, a critical component for initiating a weapon's nuclear chain reaction. Since 2007, the Lab has manufactured new pits to replace pits destroyed as part of the surveillance process of the U.S. Stockpile Stewardship Program.

Smith is driven to help complete the picture of plutonium phase stability and phase transformations, seeking to understand the mechanisms behind plutonium's erratic behavior so eventually scientists can control plutonium's behavior. At the Lujan Center, the only United States neutron scattering center that can accept highly radioactive materials samples, Smith leads the first long-term study using neutrons to observe plutonium-239's natural aging process.

"Quite a few people said the measurements wouldn't happen because I wouldn't be able to get any signal," she said. Smith said she doesn't like the word "impossible," and forged ahead, proving them wrong.

Undaunted by the numerous requirements of this complex, ongoing work, Smith said, "You tend to forget about the hardships when you accomplish a task. The next time, you rely on that experience and it doesn't seem so impossible or hard anymore."

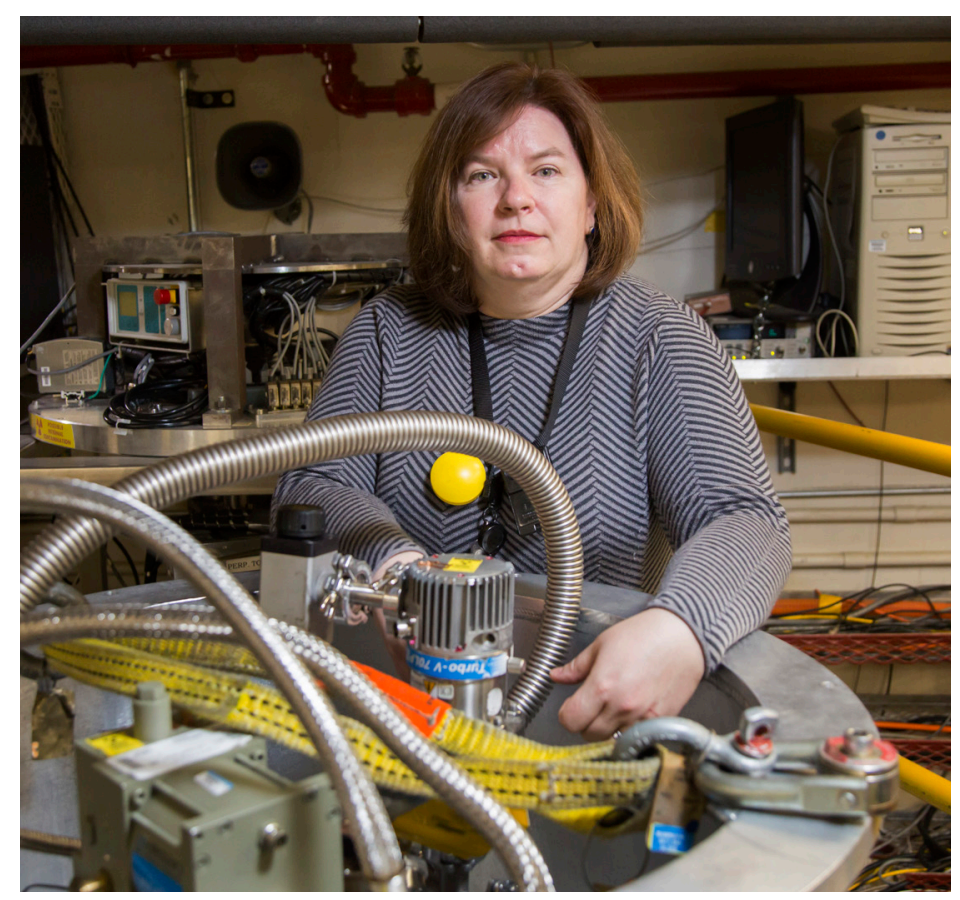

Alice Smith is using the Lujan Center's HIPPO (high-pressure/preferred orientation) diffractometer to study delta phase ${ }^{242} \mathrm{Pu}-\mathrm{Ga}$ alloys under high-pressure and high-temperature conditions.

She also characterized the plutonium sample for a notable experiment in which Los Alamos and Japanese researchers detected the faint signal of plutonium-239's nuclear magnetic resonance signature, a Rosetta stone for deciphering the atomic-scale electronic properties of the most complex element in the periodic table.

Her postdoctoral mentor, Luke Daemen, now at Oak Ridge National Laboratory, described Smith as meticulous and determined. "What stands out is Alice's deep concern for science and an extraordinary steadfastness in pursuing and resolving scientific questions despite difficulty or adversity," he said.

Smith said working at a large national lab gives her access to numerous experimental techniques and researchers from different fields. "It's hard not to be excited by science, and Los Alamos," she said, is "a great place to do science. I'm sure in 10 to 15 years we will be able to access measurements that are thought to be impossible today."

Los Alamos has proposed an experimental facility called Matter-Radiation Interactions in Extremes (MaRIE) where Smith could study materials in extreme conditions, such as temperature and pressure, and observe changes in real time. "Time-resolved experiments are a big deal because many times the changes can occur on very short time scales, and we can't see those changes with the instruments we have today," she said. 


\section{Carlos Tomé and Ricardo Lebensohn Coding and collaborating}

When they first met in 1985 at Argentina's Universidad Nacional de Rosario, Ricardo Lebensohn was an enthusiastic undergraduate physics student and Carlos Tomé an earnest first-year professor. After taking Tomé's statistical mechanics course, Lebensohn asked him to be his graduate school advisor. Through his PhD dissertation project-the development of a computational code to reliably simulate materials behavior-he forged a bond with Tomé that has stood the test of time and produced valuable, award-winning work.

"It all started with Ricardo's PhD and we expanded the code through the years," said Tomé, noting that their co-authored 1993 Acta Metallurgica et Materialia paper, "A self-consistent anisotropic approach for the simulation of plastic deformation and texture development of polycrystals: Application to zirconium alloys," recently reached the 1,000-citation mark in Google Scholar.

Drawing upon prior work by French researchers, Lebensohn reformulated the problem, making it easier and faster to investigate the behavior of metallic aggregates than with previous simulation codes, which required days to generate one result. IBM personal computers had just become powerful enough to tackle such problems, and Lebensohn wrote the viscoplastic self-consistent (VPSC) code in Fortran programming language. Graphics software not yet being available, they traced figures by hand. With a smile, Lebensohn recalled Tomé redrawing his figures, which usually weren't tidy enough for his mentor's taste.

The men fell into an efficient way of working together, one that continues as they collaborate-often conversing in Spanish with each other-as members of Materials Science in Radiation and Dynamics Extremes (MST-8).

"Ricardo likes to see results quickly: write code and do calculations," Tomé said. "I have a more contemplative attitude. I like to sleep over things and let them ferment before jumping into action."

Tomé joined the Laboratory's Center for Materials Science in 1996: Lebensohn followed in 2003. Siegfried Hecker, the center director, had launched an initiative to develop microstructural-based modeling to improve materials performance, and the VPSC approach was a good fit. Applicable to metals, minerals, and polymers, the VPSC code can help in understanding the properties of materials and inform techniques to make them inherently more reliable for the intended application and perhaps less expensive to manufacture.

At Los Alamos the ever-evolving code enables science and engineering required to establish novel design principles and manufacturing processes for advanced materials. It has helped solve challenges in forming uranium parts. In lightwater reactors, where radioactive fuel, stress variations,

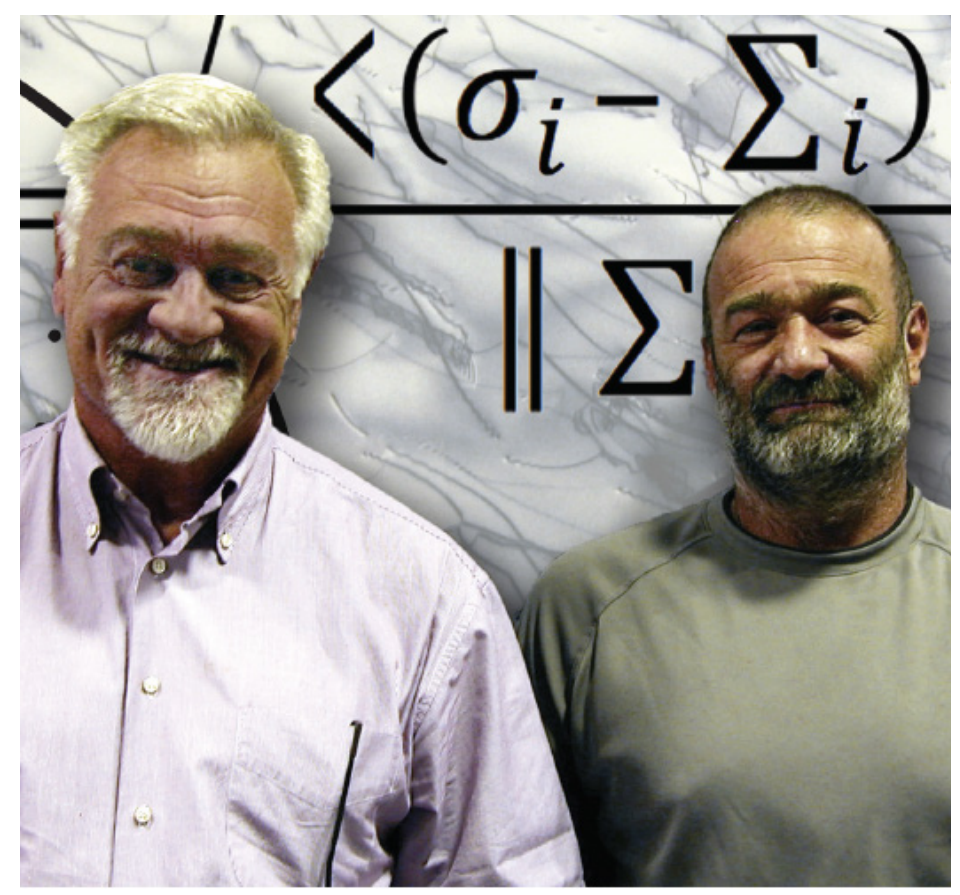

Carlos Tomé (left) and Ricardo Lebensohn recently saw their viscoplastic self-consistent code (in background) research reach 1,000 citations in Google Scholar.

and temperature fluctuations can cause structural defects that grow into fracture, the code can predict dimensional changes of fuel-cladding tubes through the lifetime of the reactor-important for fuel reliability and safety.

The VPSC code can be linked with larger finite element codes or it can be used to derive physical laws that can be expressed analytically and implemented in production codes. It simulates plastic forming and predicts flow stress, texture, and microstructure evolution associated with large strain deformation. Such predictions can help control functionality of materials in extreme environments - a chief pursuit at the Laboratory. Lebensohn said he sees the code as complementary to experiments at the Laboratory's proposed Matter-Radiation Interactions in Extremes (MaRIE) facility.

"Large instruments don't give you directly the measurement you want," he said. "You need modeling to explore the microscopic mechanisms."

The VPSC code has been distributed free of charge to more than 300 external users. Many requests come from materials scientists interested in the deformation of magnesium and from geologists wanting to infer the geological history of the Earth's interior based on signatures present in rocks' microstructure.

"If users come up with a challenging and interesting problem, we start collaborating with them," Lebensohn said. 


\section{Experimental Physical Sciences is ...}

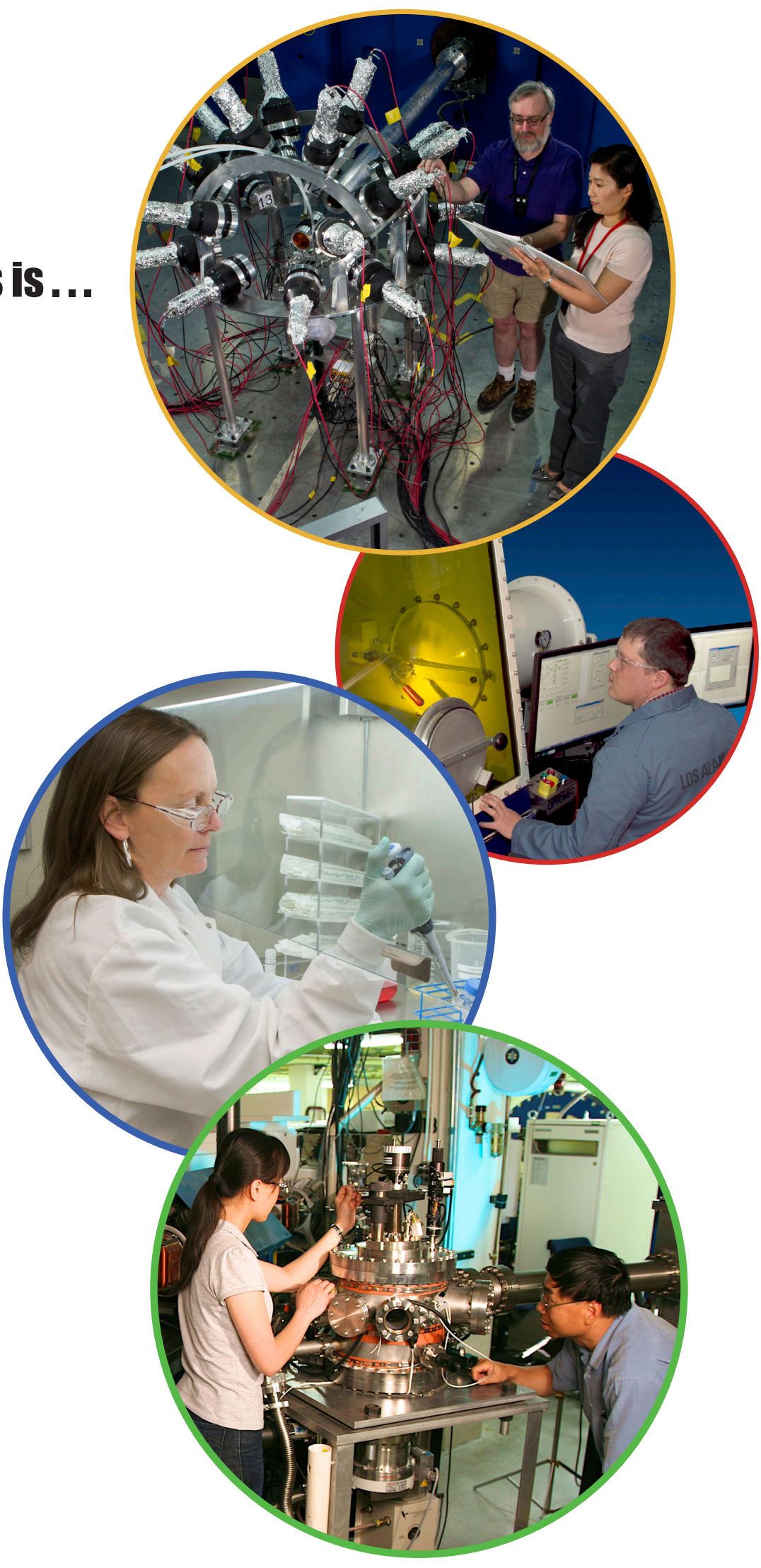

\section{Materials Physics}

and Applications

Laying the foundation for enhanced national security through

functional materials research

and device development

\section{Materials Science \\ and Technology}

Providing world-leading, innovative, and agile materials science and technology solutions for national security missions

\section{Physics}

Answering questions

about the nature of the universe and delivering solutions for

national security concerns

\section{Sigma}

Developing materials and

components in support of all

Laboratory experimental programs 
Writers: Diana Del Mauro, Kris Fronzak, Karen Kippen, Eileen Patterson

Editor: Karen Kippen

Photographers: Robb Kramer, Genevieve Martin, Richard Robinson, Carlos Trujillo, Sandra Valdez

Designers: Jim Cruz, Kris Fronzak

Experimental Physical Sciences Vitae

is a compilation of profiles that appeared in

MPA Materials Matter, MST e-NEWS,

and Physics Flash newsletters.

Experimental Physical Sciences

www.lanl.gov/adeps/

505-665-4454

Materials Physics and Applications

www.lanl.gov/mpa/

505-665-1131

Materials Science and Technology

www.lanl.gov/mst/

505-665-1535

Physics

www.lanl.gov/p/

505-667-4117

Sigma

505-667-4368 